\title{
Hydrothermal Reaction Kinetics and Pathways of Phenylalanine Alone and in Binary Mixtures
}

\author{
Shujauddin Changi, Minghan Zhu, and Phillip E. Savage ${ }^{*^{[a]}}$
}

\begin{abstract}
We examined the behavior of phenylalanine in high-temperature water (HTW) at $220,250,280$, and $350^{\circ} \mathrm{C}$. Under these conditions, the major product is phenylethylamine. The minor products include styrene and phenylethanol (1-phenylethanol and 2-phenylethanol), which appear at higher temperatures and longer batch holding times. Phenylethylamine forms via decarboxylation of phenylalanine, styrene forms via deamination of phenylethylamine, and phenylethanol forms via hydration of styrene. We quantified the molar yields of each product at the four temperatures, and the carbon recovery was between $80-100 \%$ for most cases. Phenylalanine disappearance follows first-order kinetics with an activation energy of $144 \pm$ $14 \mathrm{~kJ} \mathrm{~mol}^{-1}$ and a pre-exponential factor of $10^{12.4 \pm 1.4} \mathrm{~min}^{-1}$. A kinetics model based on the proposed pathways was consistent with the experimental data. Effects of five different salts $\left(\mathrm{NaCl}, \mathrm{NaNO}_{3}, \mathrm{Na}_{2} \mathrm{SO}_{4}, \mathrm{KCl}, \mathrm{K}_{2} \mathrm{HPO}_{4}\right)$ and boric acid $\left(\mathrm{H}_{3} \mathrm{BO}_{3}\right)$ on
\end{abstract}

phenylalanine behavior at $250^{\circ} \mathrm{C}$ have also been elucidated These additives increase phenylalanine conversion, but decrease the yield of phenylethylamine presumably by promoting formation of high molecular weight compounds. Lastly, binary mixtures of phenylalanine and ethyl oleate have been studied at $350{ }^{\circ} \mathrm{C}$ and three different molar concentration ratios. The presence of phenylalanine enhances the conversion of ethyl oleate and molar yields of fatty acid. Higher concentration of ethyl oleate leads to increased deamination of phenylethylamine and hydration of styrene. Amides are also formed due to the interaction of oleic acid/ethyl oleate and phenylethylamine/ammonia and lead to a decrease in the fatty acid yields. Taken collectively, these results provide new insights into the reactions of algae during its hydrothermal liquefaction to produce crude bio-oil.

\section{Introduction}

The world's escalating energy demands motivates the production of sustainable liquid fuels. Research is conducted in alternative and renewable sectors, and biofuels obtained from biomass is one such area. Algae are potentially promising biomass candidates. They have a higher $(\approx 20 \times)$ photosynthetic efficiency than terrestrial plants. ${ }^{[1]}$ Algae can grow in brackish and saline water, thereby reducing the competition for land with conventional food crops. ${ }^{[2]}$ Thirdly, algae have higher lipid content per area of land cultivated than other biomass sources such as soybean, sunflower, or palm oil. ${ }^{[3]}$ Lastly, microalgae cultivation can be coupled with recycling of wastewater and refinery flue gases to make the process more economical and environmentally benign.

Hydrothermal processing of algal biomass has been widely reported in the past, involving conversion of wet algal biomass to crude bio-oils, ${ }^{[2]}$ carbonized solids, ${ }^{[4,5]}$ and fuel gases. ${ }^{[6]}$ Hydrothermal liquefaction of microalgae is a potentially promising route to obtain high-energy-density, fungible advanced biofuels. This process involves treatment of algal biomass in an aqueous medium at elevated temperatures $\left(250-350^{\circ} \mathrm{C}\right)$ and pressures (1.5-17 MPa). Water has distinctly different properties at high temperatures and pressures than at ambient conditions. For example, water at high temperature and high pressure has a lower dielectric constant, higher dissociation constant, and increased solubility of organic compounds as compared to that at room temperature. ${ }^{[7]}$ Thus, biomacromolecules in algae are more susceptible to hydrolytic attack under these conditions. Hydrothermal processing is well suited for wet biomass because it obviates the need to dry the feedstock, an energy-intensive pretreatment step that lowers the overall efficiency of the process.

Algae biomass is a complex mixture of biomacromolecules such as polysaccharides, triglycerides, lipids, and proteins. ${ }^{[2]}$ It can be very challenging to understand the chemistry of hydrothermal liquefaction, if starting directly with algae. Instead, one can represent the complex biomacromolecules with simple model compounds containing the same functional groups. One expects these model compounds to behave similarly to their corresponding biomacromolecules in high temperature water (HTW). The study of biomass model compounds can provide useful insights and understanding into the reaction products, pathways, kinetics, and mechanisms of biooil production from actual biomass. However, there have been only a few previous hydrothermal reaction studies for model compounds of algal biomass. We recently reported on phytol and ethyl oleate, model compounds representing chlorophyll

\footnotetext{
[a] S. Changi, M. Zhu, P. E. Savage

Chemical Engineering Department

University of Michigan

Ann Arbor, MI 48109-2136 (USA)

Fax: (+1) 734-763-0459

E-mail:psavage@umich.edu

Supporting Information for this article is available on the WWW under http://dx.doi.org/10.1002/cssc.201200146.
} 
and ester linkages in triglycerides, respectively. ${ }^{[8-10]}$ The present study uses an amino acid as a model compound to understand the behavior of protein residues in algae during hydrothermal liquefaction.

Different strains of algae have varying composition of proteins ranging from as low as $6 \mathrm{wt} \%$ to as high as $71 \mathrm{wt} \%$ (on a dry algae basis). ${ }^{[11]}$ Leucine, valine, lysine, phenylalanine, arginine, aspartic acid, glutamine, alanine, and glycine are the major amino acids constituting various proteins in algae. ${ }^{[11]}$ During hydrothermal liquefaction, the proteins likely undergo hydrolytic depolymerization to release peptide fragments. Thus, hydrothermal liquefaction of protein-containing algae produces "bio-oil" containing either protein residues with the above amino acids or new products obtained through their reaction with other constituents of algae (e.g., glucose, triglycerides etc.) Researchers have identified indole, pyrazine, pyridine, pyrrole, and their derivatives in the bio-oil obtained from liquefaction of algae from $200-600^{\circ} C^{[2,12-15]}$ These products likely arise from different amino acids. For example, Hwang et al. ${ }^{[16]}$ have identified pyridines, pyrroles, oxazoles, and other N-containing compounds during the reaction of glucose and several amino acids in hot liquid water. To obtain a better understanding of the chemistry of bio-oil production during algae liquefaction, one needs to investigate the reactions of amino acids in HTW. We use this motivation to explore the kinetics of a model amino acid in HTW and elucidate its implications on algae liquefaction.

Several researchers have studied the behavior of different amino acids in HTW. ${ }^{[17-30]}$ Vallentyne ${ }^{[17]}$ studied the decomposition of several amino acids under subcritical water conditions $\left(T<243^{\circ} \mathrm{C}\right)$ and modeled the decarboxylation of amino acids using first-order kinetics. Despite the great efforts made in his research, he faced many technological problems due to the breaking of glass reactors used in his work. Others too have mentioned decarboxylation as the main reaction of alanine and glycine in HTW and reported first-order rate constants. ${ }^{[18-20]}$

Sato et al. ${ }^{[22]}$ measured the decomposition of five amino acids (alanine, leucine, phenylalanine, serine, and aspartic acid) at $200-340^{\circ} \mathrm{C}, 20 \mathrm{MPa}$, and $20-180 \mathrm{~s}$. They reported that decarboxylation to amines and deamination to organic acids were the two main pathways under these conditions. These authors suggest that alanine and glycine are produced as intermediates from serine. However, a limitation that prevents their work from being more useful for learning about algae liquefaction is the short residence times $(<3 \mathrm{~min})$ used.

Klingler et al. ${ }^{[23]}$ studied alanine and glycine in hydrothermal conditions at $250-450^{\circ} \mathrm{C}, 34$ and $24 \mathrm{MPa}$, and a residence time of 2.5-3.5 s. They too found organic acids and amines as the main products of reactions, but they also suggest that glycine could dimerize to diketopoperazine. Other researchers have also reported trimers and tetramers of glycine and alanine at 200-350 ${ }^{\circ} \mathrm{C}$, $15-40 \mathrm{MPa}$, and $120 \mathrm{s.}^{[31-33]} \mathrm{Cox}$ and Seward ${ }^{[24]}$ used a custom-built spectrophotometric cell and in situ observation to report dimerization and subsequent cyclization of alanine and glycine. They also fit the oligomerization kinetics of these amino acids to their experimental data using various reaction orders and concluded that the best fit was obtained when oligomerization followed second-order kinetics. However, their study was conducted only at low temperatures from $120-165^{\circ} \mathrm{C}$. In a recent study, Otake et al. ${ }^{[34]}$ reported oligomers up to pentamers for alanine and glycine at high temperatures $\left(180-400^{\circ} \mathrm{C}\right)$, reaction times from 2 to $24 \mathrm{~h}$, and high pressure (1.0-5.5 GPa) without using a catalyst. However, these authors do not report rate constants for these oligomerization reactions starting from amino acids. Otake et al. ${ }^{[34]}$ also report that under their experimental conditions, deamination of amino acids was favored over decarboxylation. They attribute this difference in the pathways between their work and that of others ${ }^{[17-20]}$ to the high pressures (several $\mathrm{GPa}$ ) used in their work. Sakata et al. ${ }^{[35]}$ studied the effect of $\mathrm{pH}$ on the dimerization rate of glycine under hydrothermal conditions. They have shown that the rate of dimerization increases with $\mathrm{pH}$, with a maximum rate occurring at $\mathrm{pH}$ of 9.8 and $150^{\circ} \mathrm{C}$.

Abdelmoez et al. ${ }^{[25,26]}$ studied the kinetics of 17 amino acids in saturated subcritical water $\left(230-290^{\circ} \mathrm{C}\right)$, batch holding times ranging from $2.5-40 \mathrm{~min}$, both individually and as mixtures. Glycine, alanine, valine, and proline were produced as intermediate products from other amino acids in their study. For phenylalanine in HTW, the authors proposed a deamination pathway due to the formation of formic acid, carbonic acid, and ammonia. However, these authors may have overlooked the possibility of carbonic acid formation due to a decarboxylation pathway. They also reported that amino acids in mixtures were less stable and that their activation energies decreased. Furthermore, they conducted a $\mathrm{pH}$ study and found most amino acids to be labile at acidic and near-neutral $\mathrm{pH}$ values but more stable at basic $\mathrm{pH} 10 . \mathrm{Li}$ and co-workers ${ }^{[28-30]}$ have studied the kinetics of decarboxylation of aliphatic amino acids, effects of different side chain constituents, and effect of $\mathrm{pH}$ on the hydrothermal stability of these amino acids at 270$340^{\circ} \mathrm{C}$ using an FTIR spectroscopy flow reactor. They are also the only research group, to the best of our knowledge, to have studied the effect of addition of salt $(\mathrm{KCl})$ on hydrothermal decarboxylation. ${ }^{[28]}$ They found that the decarboxylation rate for $\alpha$-alanine decreases with addition of $\mathrm{KCl}$. They hypothesized that either the transition state was less polar than the zwitterionic reactant due to solvent association on addition of salt or that $\mathrm{K}^{+}$or $\mathrm{Cl}^{-}$ions formed complexes with the ionic sites of $\alpha$-alanine thereby reducing its activity. However, the authors presented no detailed work to support their hypothesis.

Although a number of studies exist on the behavior of amino acids in HTW, there is a gap in the literature because no detailed characterization of products, pathways, and kinetics at high temperatures and longer batch holding times have been carried out in the past. To the best of our knowledge, no study has been reported for amino acids above $340^{\circ} \mathrm{C}$ and at times longer than $3 \mathrm{~min}$. These longer times are very relevant for hydrothermal liquefaction of algae because they lead to maximum yields of bio-oil. There has been no previous detailed exploration of all the possible products and pathways that may arise from amino acids under these conditions. Furthermore, different pathways, decarboxylation and deamination, have 
been reported previously for reaction of amino acids in HTW but only on the basis of measuring carbon dioxide product yields. Measuring carbon dioxide evolution alone is not sufficient. Other products from amino acid reaction in and with HTW should be thoroughly identified to obtain a proper understanding of the reaction pathways. Furthermore, most of these previous studies are devoted to understanding primarily the behavior of simple amino acids such as alanine and glycine and not the more complicated amino acids.

It is interesting to note that dried algal biomass contains salts in varying amounts (5-20 wt $\%$ ash content). ${ }^{[2,36]}$ To the best of our understanding, only Li et al. ${ }^{[28]}$ has previously studied the effect of salts on amino acid reaction pathways and kinetics in water at high temperatures. It is possible that addition of salts could accelerate the decomposition of amino acids as is evident during hydrothermal gasification reactions of amino acids or other carbon containing compounds. ${ }^{[37-40]}$

Lastly, given the broad motivation to better understand reactions occurring during hydrothermal liquefaction of algae, mixtures of organic compounds need to be studied in HTW. It is quite possible that a mixture of organic compounds may give new products that are otherwise not observed when working with individual model compounds. To the best of our knowledge, glucose is the only organic compound that has been studied along with amino acids in high-temperature, high-pressure water. ${ }^{[41-43]}$ Peterson et al. ${ }^{[41]}$ showed that a binary mixture of glucose and glycine at $250^{\circ} \mathrm{C}$ and $10 \mathrm{MPa}$ undergoes the Maillard reaction, where the sugar and amino acid combine to form the so-called Amadori compound. This product then undergoes a number of reactions to form polymeric compounds referred to as melanoidins. The authors also showed that the presence of glucose accelerated glycine disappearance, whereas the presence of glycine either increased or decreased glucose decomposition (depending on the initial glycine concentration). Clearly, the binary mixture behaves differently than either of the starting model compounds. Kruse et al. ${ }^{[42,43]}$ have studied the influence of alanine on glucose in the presence of potassium salts but for hydrothermal gasification carried from $460-550^{\circ} \mathrm{C}$ at $25 \mathrm{MPa}$ for reaction times between 5-9 s. They found that the gas yields decrease in the presence of amino acids and the dissolved organic carbon content increases, which they also attributed to the Maillard reaction.

To sum up, this critical assessment of the literature shows that information about the behavior of amino acids at hydrothermal liquefaction conditions, the influence of salts, and the influence of organic mixtures is not readily available. Such information would provide a better understanding of hydrothermal liquefaction of algae. Therefore, we report herein on the kinetics of phenylalanine in high temperature water from 220 $350^{\circ} \mathrm{C}$, including a thorough product identification, quantification, and examination of possible pathways operative under these conditions. We also report on the effects of various inorganic compounds commonly used in the culture media for algae ( $\mathrm{NaCl}, \mathrm{NaNO}_{3}, \mathrm{Na}_{2} \mathrm{SO}_{4}, \mathrm{KCl}, \mathrm{K}_{2} \mathrm{HPO}_{4}$ ), and boric acid $\left(\mathrm{H}_{3} \mathrm{BO}_{3}\right)$, on phenylalanine behavior in HTW. Finally, we report on the reactions of a binary mixture of ethyl oleate and phenylalanine at $350^{\circ} \mathrm{C}$ from $10-60 \mathrm{~min}$.

We selected phenylalanine as the model amino acid because 1) phenylalanine is one of the most abundant amino acids in algae; 2 ) phenylalanine has an aryl substituent on a $\beta$-alanine backbone, which might lead to previously unexplored steric or electronic effects; 3) phenylalanine has not been previously studied in great detail in HTW; and 4) phenylalanine and its products have better sensitivity and ease of detection by HPLC and GC. The binary system of ethyl oleate and phenylalanine was chosen because of the work reported for these individual model compounds previously and herein..$^{[8,9]}$

\section{Results and Discussion}

In this section, we first describe preliminary work that was performed to validate the experimental methods. We then report the product distribution, elucidate the reaction pathways, and develop a corresponding quantitative phenomenological kinetics model. Lastly, we note the results pertaining to the binary mixtures of phenylalanine with salts (or boric acid) and with ethyl oleate.

Control experiments were performed to assess our ability to measure accurately the amount of phenylalanine in the reactor. These experiments, which were essentially a run performed at room temperature, resulted in a phenylalanine recovery of 98 and $95 \%$ without and with $\mathrm{K}_{2} \mathrm{HPO}_{4}$, respectively, thereby verifying the suitability of the methods used for quantifying the amount of phenylalanine.

\section{Reaction products}

The product molar yields and phenylalanine conversion at different times and temperatures are presented in Table 1. Phenylethylamine was the major product at all but the most severe conditions examined. Small amounts of styrene and phenylethanol formed as minor products when conversion was $<95 \%$. Both 1- and 2-phenylethanol appeared in these experiments, but we summed their yields and report that sum hereafter as phenylethanol. To the best of our knowledge, neither styrene nor phenylethanol has been reported previously as a product from hydrothermal treatment of phenylalanine.

The yields of phenylethylamine increased with increasing batch holding times for runs at 220,250 , and $280^{\circ} \mathrm{C}$. The highest yield for phenylethylamine was about 0.68 at $280^{\circ} \mathrm{C}$ and $60 \mathrm{~min}$. At $350^{\circ} \mathrm{C}$, the yield of phenylethylamine increased from 0.36 at $5 \mathrm{~min}$ to 0.62 at $10 \mathrm{~min}$ and then decreased thereafter. This behavior suggests that phenylethylamine decomposes to secondary products under severe conditions. The yields of styrene were low $(<0.01)$ at 220,250 , and $280^{\circ} \mathrm{C}$ (until $30 \mathrm{~min}$ ). However, the yield of styrene increased to 0.044 at $280^{\circ} \mathrm{C}$ and $60 \mathrm{~min}$. At $350^{\circ} \mathrm{C}$ the yield of styrene increased from 0.001 at $5 \mathrm{~min}$ to 0.38 at $60 \mathrm{~min}$. At this condition, the yield of styrene exceeded that of phenylethylamine, and styrene was the major product.

Phenylethanol was not formed in yields exceeding 0.003 except at longer batch holding times at $350^{\circ} \mathrm{C}$. At this temper- 


\begin{tabular}{|c|c|c|c|c|c|c|}
\hline $\begin{array}{l}T \\
{\left[{ }^{\circ} \mathrm{C}\right]}\end{array}$ & $\begin{array}{l}t \\
{[\mathrm{~min}]}\end{array}$ & $\begin{array}{l}\text { Phenylalanine } \\
\text { conversion }\end{array}$ & $\begin{array}{l}\text { Yield } \\
\text { phenylethylamine }\end{array}$ & styrene & phenylethanol & $\begin{array}{l}\text { Carbon } \\
\text { balance [\%] }\end{array}$ \\
\hline \multirow{5}{*}{220} & 60 & 0.12 & 0.10 & 0.0012 & 0 & 99 \\
\hline & 120 & 0.20 & 0.10 & 0.0012 & 0 & 90 \\
\hline & 150 & $0.23 \pm 0.04$ & $0.11 \pm 0.01$ & $0.0012 \pm 0.0001$ & 0 & $89 \pm 4$ \\
\hline & 180 & 0.25 & 0.12 & 0.0012 & 0.0011 & 87 \\
\hline & 240 & 0.27 & 0.13 & 0.0013 & 0.0018 & 88 \\
\hline \multirow{5}{*}{250} & 30 & $0.33 \pm 0.03$ & $0.20 \pm 0.04$ & $0.0006 \pm 0.0005$ & $0.0018 \pm 0.0010$ & $88 \pm 8$ \\
\hline & 60 & $0.53 \pm 0.04$ & $0.28 \pm 0.04$ & $0.0016 \pm 0.0010$ & $0.0017 \pm 0.0010$ & $77 \pm 11$ \\
\hline & 90 & $0.60 \pm 0.02$ & $0.38 \pm 0.01$ & $0.0029 \pm 0.0010$ & $0.0010 \pm 0.0010$ & $86 \pm 3$ \\
\hline & 120 & 0.66 & 0.41 & 0.0045 & 0.0014 & 84 \\
\hline & 150 & 0.70 & 0.41 & 0.0053 & 0.0016 & 80 \\
\hline \multirow{7}{*}{280} & 180 & 0.73 & 0.44 & 0.0070 & 0.0017 & 81 \\
\hline & 10 & 0.62 & 0.43 & 0.0018 & 0 & 85 \\
\hline & 15 & 0.80 & 0.55 & 0.0033 & 0 & 80 \\
\hline & 20 & 0.84 & 0.59 & 0.0052 & 0 & 82 \\
\hline & 30 & $0.91 \pm 0.01$ & $0.64 \pm 0.01$ & $0.0135 \pm 0.0005$ & $0.0014 \pm 0.0004$ & $81 \pm 1$ \\
\hline & 40 & 0.95 & 0.67 & 0.0273 & 0.0022 & 80 \\
\hline & 60 & 0.97 & 0.68 & 0.0448 & 0.0030 & 81 \\
\hline \multirow{7}{*}{350} & 5 & 0.63 & 0.36 & 0.0009 & 0.0015 & 76 \\
\hline & 10 & $1.00 \pm 0.003$ & $0.62 \pm 0.03$ & $0.0902 \pm 0.0200$ & $0.0016 \pm 0.0003$ & $68 \pm 9$ \\
\hline & 15 & 1.00 & 0.60 & 0.0703 & 0.0033 & 70 \\
\hline & 20 & 1.00 & $0.45 \pm 0.05$ & $0.2006 \pm 0.0500$ & $0.0124 \pm 0.0020$ & $64 \pm 3$ \\
\hline & 30 & 1.00 & $0.33 \pm 0.04$ & $0.2704 \pm 0.0400$ & $0.0244 \pm 0.0040$ & $61 \pm 5$ \\
\hline & 40 & 1.00 & 0.30 & 0.2802 & 0.0242 & 57 \\
\hline & 60 & 1.00 & 0.23 & 0.3806 & 0.0342 & 60 \\
\hline
\end{tabular}

The residual for minimization was the summation of squared errors (SSE) between the calculated $\left(C_{\text {mod }}\right)$ and experimental $\left(C_{\text {exp }}\right)$ phenylalanine concentrations [Eq. (2)].

$\mathrm{SSE}=\sum_{j}\left[C_{j, \bmod }-C_{j, \exp }\right]^{2}$

$j$ is the number of discrete reaction times at any particular temperature. A non-linear regression was carried out using the SOLVER add-in in Excel 2007, to obtain the values of $k_{n}$ and $n$, as displayed in Table 2 . The reaction order for phenylalanine is almost unity at all temperatures under consideration, which is consistent with previous work. Hence, we reanalyzed the data using first-order kinetics to obtain the corresponding firstorder rate constants $\left(k_{\text {first }}\right)$ at different temperatures (Table 2).

ature the yield of phenylethanol increased from about 0.002 at $5 \mathrm{~min}$ to nearly 0.034 at $60 \mathrm{~min}$.

The conversion of phenylalanine was below $30 \%$ at mild conditions [e.g., $\left.220^{\circ} \mathrm{C}(<240 \mathrm{~min}), 250^{\circ} \mathrm{C}(<30 \mathrm{~min})\right]$. In general, the conversion increased with both temperature and time. Nearly complete conversion was observed at $280^{\circ} \mathrm{C}$ at a batch holding time of $60 \mathrm{~min}$ and at $350^{\circ} \mathrm{C}$ for batch holding times greater than 10 min.

The carbon balance was $90 \% \pm 10 \%$ in most cases, and fell below $80 \%$ only for experiments at $350{ }^{\circ} \mathrm{C}$. The conversion of phenylalanine was very high under these conditions. It is likely that the more severe conditions led to the formation of higher molecular weight products via oligomerization, as will be explained in the next section. It should be noted that there was considerable gas formation (most likely carbon dioxide), especially under severe conditions. Although we have not quantified $\mathrm{CO}_{2}$, we account for it in the carbon balance by assuming its yield was equal to the yield of phenylethylamine, since $\mathrm{CO}_{2}$ would form in parallel with phenylethylamine during the decarboxylation of phenylalanine.

To compare the present rate data for the disappearance of phenylalanine (PA) with previous work, ${ }^{[17,25,29]}$ which indicated first-order kinetics, we fit the phenylalanine conversion data of Table 1 to Equation (1), which is the integrated form of the batch reactor design equation coupled with an $n^{\text {th }}$-order rate equation, and $k_{n}$ is the $n^{\text {th }}$-order rate constant.

$C_{\mathrm{PA}}=\left[C_{\mathrm{PA}, \text { initial }}^{(1-n)}-(1-n) k_{n} t\right]^{\left(\frac{1}{1-n}\right)}$

\begin{tabular}{|cccc|}
\hline \multicolumn{4}{|c|}{ Table 2. Rate constant and order for phenylalanine disappearance. } \\
$T\left[{ }^{\circ} \mathrm{C}\right]$ & Reaction order $(n)$ & $k_{n}[\mathrm{~mol}, \mathrm{~min}, \mathrm{~L}]$ & $k_{\text {first }}\left[\mathrm{min}^{-1}\right]$ \\
\hline 220 & 0.94 & 0.0008 & 0.0015 \\
250 & 0.97 & 0.0065 & 0.0083 \\
280 & 0.98 & 0.0600 & 0.0692 \\
\hline
\end{tabular}

An Arrhenius plot (based on first-order rate constants) gave rise to an activation energy of $144 \pm 14 \mathrm{~kJ} \mathrm{~mol}^{-1}$ and a pre-exponential factor of $10^{12.4 \pm 1.4} \mathrm{~min}^{-1}$. Table 3 compares these Ar-

\begin{tabular}{|c|c|c|c|}
\hline Source & $A_{0}\left[\min ^{-1}\right]$ & $E_{\mathrm{a}}\left[\mathrm{kJ} \mathrm{mol}^{-1}\right]$ & $k_{250^{\circ} \mathrm{C}}\left[\mathrm{min}^{-1}\right]$ \\
\hline this work & $10^{12.4 \pm 1.4}$ & $144 \pm 14$ & $8.3 \cdot 10^{-3}$ \\
\hline Li and Brill ${ }^{[29]}$ & $10^{15.1 \pm 2.5}$ & $171 \pm 8$ & $9.5 \cdot 10^{-3}$ \\
\hline Abdelmoez $^{[25]}$ & $10^{10.5}$ & 126 & $9.2 \cdot 10^{-3}$ \\
\hline Vallentyne $e^{[17]}$ & $10^{10.1}$ & 129 & $1.4 \cdot 10^{-3}$ \\
\hline
\end{tabular}

rhenius parameters with those reported previously for phenylalanine in HTW. Although there is some variability in the Arrhenius parameters, the rate constants calculated at a given temperature $\left(250^{\circ} \mathrm{C}\right.$ is used in Table 3$)$ in this work compare very well with those calculated using the Arrhenius parameters reported by Li and Brill ${ }^{[29]}$ and Abdelmoez et al. ${ }^{[25]}$ The small differences between these parameter values can arise due to the differences in operating temperatures, pressures, process 
times, and procedures by which the data is collected. These rate constants, however, are six to seven times higher than that calculated using the Arrhenius parameters reported by Vallentyne. ${ }^{[17]} \mathrm{Li}$ and Brill ${ }^{[30]}$ had also noted discrepancies between their rate constants and those computed by Vallentyne $^{[17]}$ for other amino acids, such as glycine. They attribute these discrepancies to differences in the reactor surface materials. Li and Brill used a titanium flow cell, whereas Vallentyne used glass reactors. The analytical procedures used by Vallentyne were not as advanced as the current methods for quantification, which could also result in some discrepancies between the rate constants.

\section{Reaction pathways}

The previous section showed that phenylalanine in HTW produced phenylethylamine as its main product, whereas styrene and phenylethanol were produced in minor amounts at most of the conditions under consideration. However, at $350^{\circ} \mathrm{C}$ and $60 \mathrm{~min}$, the yield of styrene becomes greater than that of phenylethylamine. We desired to discover the complete set of reaction pathways for phenylalanine and these products.

Phenylethylamine can form via decarboxylation of phenylalanine. Decarboxylation mechanisms for amino acids can be complicated and several have been proposed. Direct decarboxylation of the zwitterions of carboxylic acid and carboxylate ion, such as occurs in amino acids, has been reported. ${ }^{[30,44-46]}$ $\mathrm{Li}$ and $\mathrm{Brill}^{[30]}$ mentioned that an aromatic ring at the $\beta$-carbon can act as an electron sink that dissipates the developing negative charge on the $\alpha$-carbon atom during the decarboxylation reaction, as would be applicable for phenylalanine. Researchers have also proposed a general water-molecule-catalyzed transition state involving a six-membered ring for decarboxylation. ${ }^{[30,47,48]}$

Styrene or a corresponding alkene has not been reported in the past as a product from amino acid conversion in HTW. We hypothesize that phenylethylamine undergoes deamination at severe conditions to form styrene because the yield of phenylethylamine decreases and the yield of styrene increases. To test this hypothesis, we reacted phenylethylamine $(20 \mu \mathrm{L}$; or $0.16 \mathrm{mmol}$ equivalent to the amount of phenylethylamine formed at complete conversion of phenylalanine) in water at $350^{\circ} \mathrm{C}$ and $30 \mathrm{~min}$. The phenylethylamine conversion was $0.51 \pm 0.04$, and the yield of styrene was $0.31 \pm 0.02$. The above results indicate formation of styrene as a secondary product (from phenylethylamine) during treatment of phenylalanine in HTW.

Phenylethanol isomers, which were minor products, could be obtained via hydration of styrene in HTW. 1-phenylethanol, which can form via Markovnikov's rule, was more abundant than 2-phenylethanol, the anti-Markovnikov product. These observations are consistent with An et al., ${ }^{[49]}$ who report hydration of some olefins without any added catalysts at $250^{\circ} \mathrm{C}$ in high temperature water and also mention that the alcohol formed via Markovnikov's rule is the more abundant alcohol. We tested whether this pathway would be operative for styrene by reacting styrene $(20 \mu \mathrm{L}, 0.15 \mathrm{mmol})$ in $\mathrm{HTW}$ at $350^{\circ} \mathrm{C}$ and $30 \mathrm{~min}$. Styrene conversion under these conditions was 0.35 , forming phenylethanol in a yield of 0.05 . It is interesting to note that under these conditions styrene mostly formed several high molecular weight products, including 1,3-diphenylbutane, a styrene dimer. Styrene oligomerization under these conditions is reasonable. Erdmenger et al. ${ }^{[50]}$ reported polymerization of styrene under near-critical-water conditions to produce polystyrene, with a number-average molecular weight $\left(M_{\mathrm{n}}\right)$ of $25790 \mathrm{Da}$, in yields of 0.31 . They mentioned that polystyrene has a high decomposition temperature ( $\approx 310^{\circ} \mathrm{C}$ ) and thus can be polymerized up to $300^{\circ} \mathrm{C}$. Furthermore, the polymerization of styrene is auto-initiating at high temperatures. ${ }^{[51]}$

We also expect that phenylethanol can dehydrate in HTW to form styrene. There is ample evidence in the literature for alcohol dehydration in HTW. ${ }^{[52-54]}$

Similar to styrene, phenylalanine could also dimerize at high temperatures and longer batch holding times, as it has been mentioned for other amino acids. ${ }^{[2,31-34]}$ LC-MS chromatograms of the products from phenylalanine at $250^{\circ} \mathrm{C}$ and $30 \mathrm{~min}$ and at $350^{\circ} \mathrm{C}$ and $60 \mathrm{~min}$ (Figure 1) indicate the presence of not only phenylethylamine (main decarboxylation product), but also oligomers of phenylalanine (up to $706 \mathrm{amu}$ ).

Comparing Figure $1 \mathrm{a}$ and $1 \mathrm{~b}$ shows that more of the higher molecular weight oligomers are obtained at the higher temperature and longer batch holding time. Since we did not quantify the yields of the many oligomers of phenylalanine and styrene, the carbon balances shown in Table 1 are not $100 \%$. The propensity for more oligomerization at the higher temperatures and longer times is consistent with the carbon balance being lower at more severe conditions.

Based on the reasoning provided in this section, we propose the reaction network in Scheme 1 to describe the reactions of phenylalanine in high temperature water. The reactions include decarboxylation, hydration/dehydration, and oligomerization, all of which have been previously documented in HTW.

\section{Kinetics model}

The reaction network in Scheme 1 provides different pathways that interconnect the observed reaction products. Our focus now turns to constructing a chemical kinetics model based on the reaction network. All reactions in the network were treated as being irreversible and proceeding through first-order kinetics, except oligomerization of phenylalanine, which was taken to follow second-order kinetics, as suggested by Cox and Seward ${ }^{[24]}$ for alanine and glycine. The model can be represented by differential equations [given through Eqs. (3)-(6)], which apply to reactions in a constant-volume batch reactor.

$$
\begin{aligned}
& \frac{\mathrm{d} C_{\mathrm{PA}}}{\mathrm{d} t}=-k_{1} C_{\mathrm{PA}}-k_{4} C_{\mathrm{PA}}^{2} \\
& \frac{\mathrm{d} C_{\mathrm{PEA}}}{\mathrm{d} t}=k_{1} C_{\mathrm{PA}}-k_{2} C_{\mathrm{PEA}} \\
& \frac{\mathrm{d} C_{\mathrm{STY}}}{\mathrm{d} t}=k_{2} C_{\mathrm{PEA}}-k_{3} C_{\mathrm{STY}}-k_{5} C_{\mathrm{STY}}+k_{6} C_{\mathrm{PEOH}}
\end{aligned}
$$


a)

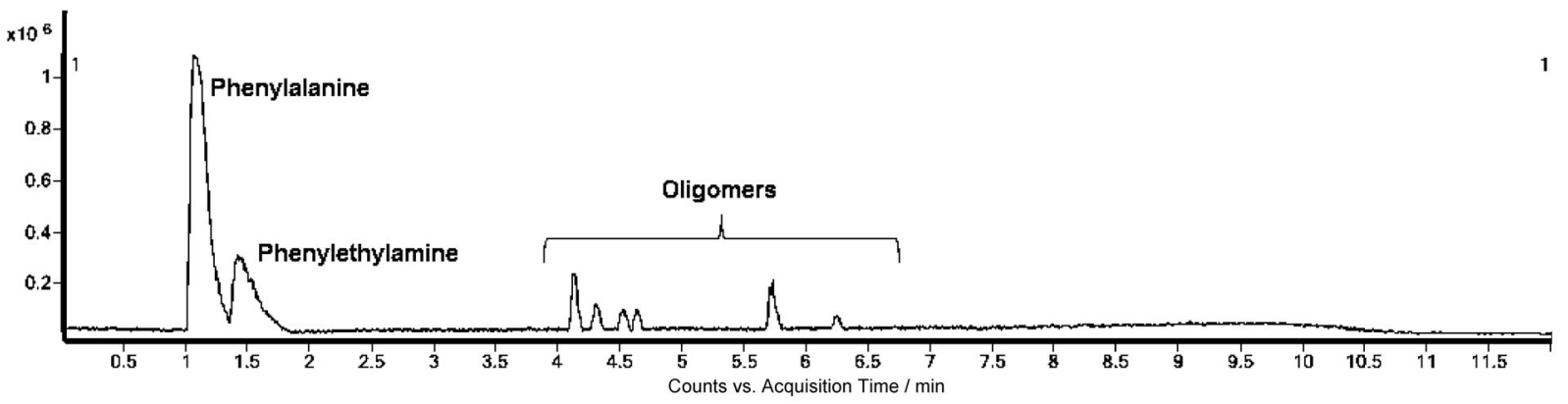

b) $\times 10$

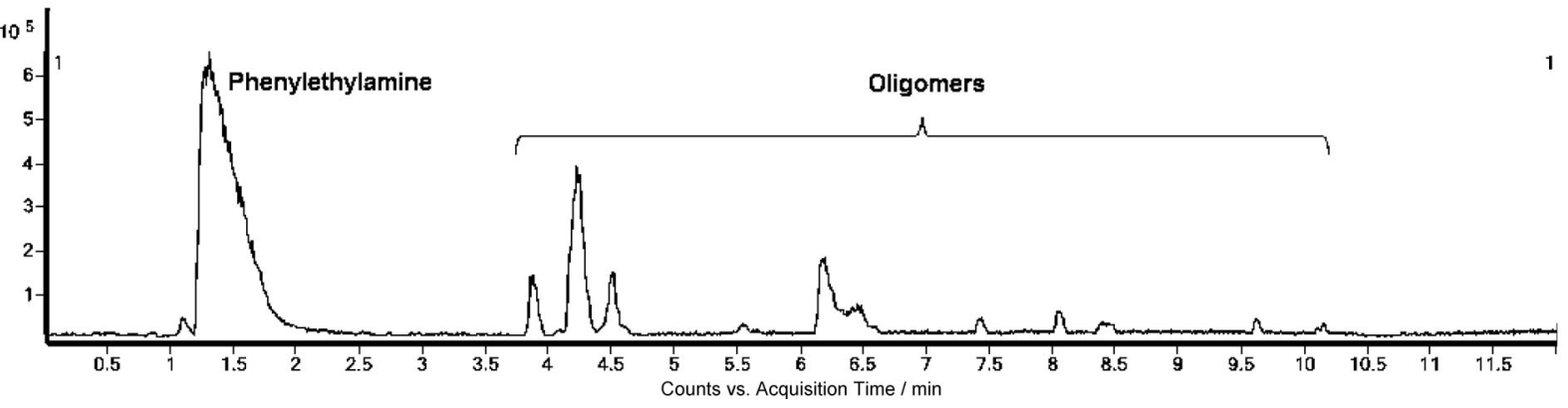

Figure 1. LC-MS chromatograms for phenylalanine reaction products at a) $250^{\circ} \mathrm{C}$ and $30 \mathrm{~min}$, and b) $350^{\circ} \mathrm{C}$ and $60 \mathrm{~min}$.

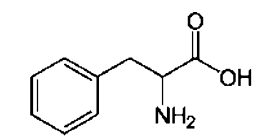

Phenylalanine

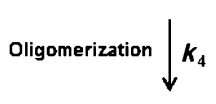

High Molecular Weight Lumped Products

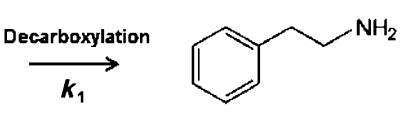

Phenylethylamine

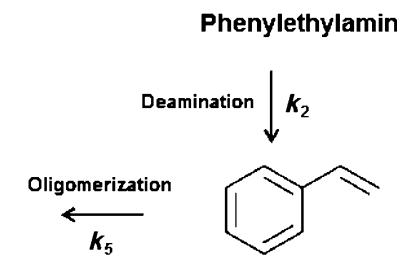

Styrene

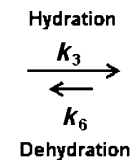

Dehydration<smiles>OCCc1ccccc1</smiles>

2-Phenylethanol<smiles>CC(O)c1ccccc1</smiles>

1-Phenylethanol

Scheme 1. Reaction pathways for phenylalanine in HTW.

$\frac{\mathrm{d} C_{\mathrm{PEOH}}}{\mathrm{d} t}=k_{3} C_{\mathrm{STY}}-k_{6} C_{\mathrm{PEOH}}$

where, $C$ is the concentration and the subscripts PA, PEA, STY, and $\mathrm{PEOH}$ represent phenylalanine, phenylethylamine, styrene, and phenylethanol, respectively. Each of the rate constants $k_{i}$ can be expressed in Arrhenius form given by Equation (7).

$k_{i}=A_{i} \exp \left(-\frac{E_{\mathrm{a}_{i}}}{\mathrm{RT}}\right)$

We used MATLAB 2010 to solve simultaneously the set of ordinary differential equations above and perform parameter estimation to obtain the values of $A_{i}$ and $E_{\mathrm{a}_{i}}$ (12 parameters total). We used fmincon to perform the optimization using the optimtool GUI. The minimization algorithm uses a sequential quadratic programming active set optimization method. ${ }^{[5]}$ The objective function for minimization was the summation of squared relative error (SSRE) between the calculated and ex- perimental product concentrations at a given reaction temperature. This quantity was calculated using Equation (8).

$$
\text { SSRE }=\sum_{j} \sum_{i=1}^{4}\left[\frac{C_{j, i, \bmod }-C_{j, i, \text { exp }}}{\left(C_{j, i, \bmod }+C_{j, i, \text { exp }}\right) / 2}\right]^{2}
$$

$j$ is the number of discrete reaction times at a particular temperature and $i$ is the number of components. The rate constants at each temperature were then fit to the linearized form of the Arrhenius equation to obtain $A_{i}$ and $E_{a_{i}}$ along with the associated standard errors for each rate constant.

Table 4 displays the Arrhenius parameters that provided the best description of the experimental data. It also displays the values of the rate constants at $250^{\circ} \mathrm{C}$ so that the relative rates of the different paths can be easily discerned. The rate constant for decarboxylation, $k_{1}$, is the largest of the first-order rate constants at all temperatures. It is also larger than the pseudo-first-order rate constant for oligomer formation from 


\begin{tabular}{|c|c|c|c|c|}
\hline $\begin{array}{l}\text { Rate constant }\left(k_{i}\right) \\
\text { in Scheme } 1\end{array}$ & Units of $A_{i}, k_{i}$ & $A_{i}$ & $\begin{array}{l}E_{\mathrm{a}} \\
{\left[\mathrm{kJ} \mathrm{mol}^{-1}\right]}\end{array}$ & $k_{i, 250^{\circ} \mathrm{C}}$ \\
\hline 1 & $\min ^{-1}$ & $10^{12.5 \pm 0.6}$ & $146 \pm 6$ & $7.49 \cdot 10^{-3}$ \\
\hline 2 & $\min ^{-1}$ & $10^{7.7 \pm 1.1}$ & $113 \pm 11$ & $2.77 \cdot 10^{-4}$ \\
\hline 3 & $\min ^{-1}$ & $10^{10.6 \pm 0.3}$ & $155 \pm 4$ & $1.12 \cdot 10^{-5}$ \\
\hline 4 & $\mathrm{Lmol}^{-1} \mathrm{~min}^{-1}$ & $10^{13.9 \pm 4.3}$ & $153 \pm 12$ & $4.17 \cdot 10^{-2}$ \\
\hline 5 & $\min ^{-1}$ & $10^{7.3 \pm 0.4}$ & $132 \pm 4$ & $1.25 \cdot 10^{-6}$ \\
\hline 6 & $\min ^{-1}$ & $10^{8.5 \pm 0.5}$ & $140 \pm 6$ & $3.23 \cdot 10^{-6}$ \\
\hline
\end{tabular}

mine, styrene, and phenylethanol at all four temperatures investigated. The model accurately describes the trends in the data and typically provides the species concentrations within experimental errors.

\section{Binary mixtures of inorganics and phenylalanine}

The previous section showed the behavior of phenylalanine in pure HTW. As mentioned in the introduction, one of the objectives in this article is to discover the influence of various inorganic compounds phenylalanine $\left(k_{4} C_{\mathrm{PA} \text {,initial }} \approx 3 \cdot 10^{-3} \mathrm{~min}^{-1}\right)$. These observations indicate that decarboxylation of phenylalanine to phenylethylamine is always the main pathway. The rate constants $k_{2}$ and $k_{3}$, which govern the formation of styrene and phenylethanol, are one and two orders of magnitude lower than $k_{1}$ at $250^{\circ} \mathrm{C}$. This result is consistent with the products being in low yields at this temperature. The rate constants $k_{5}$ and $k_{6}$ are three orders of magnitude lower than that for decarboxylation of phenylalanine, consistent with the pathways for styrene oligomerization and dehydration of phenylethanol being the minor ones.

Figure 2 shows the experimental concentrations and those calculated from the model for phenylalanine, phenylethyla-
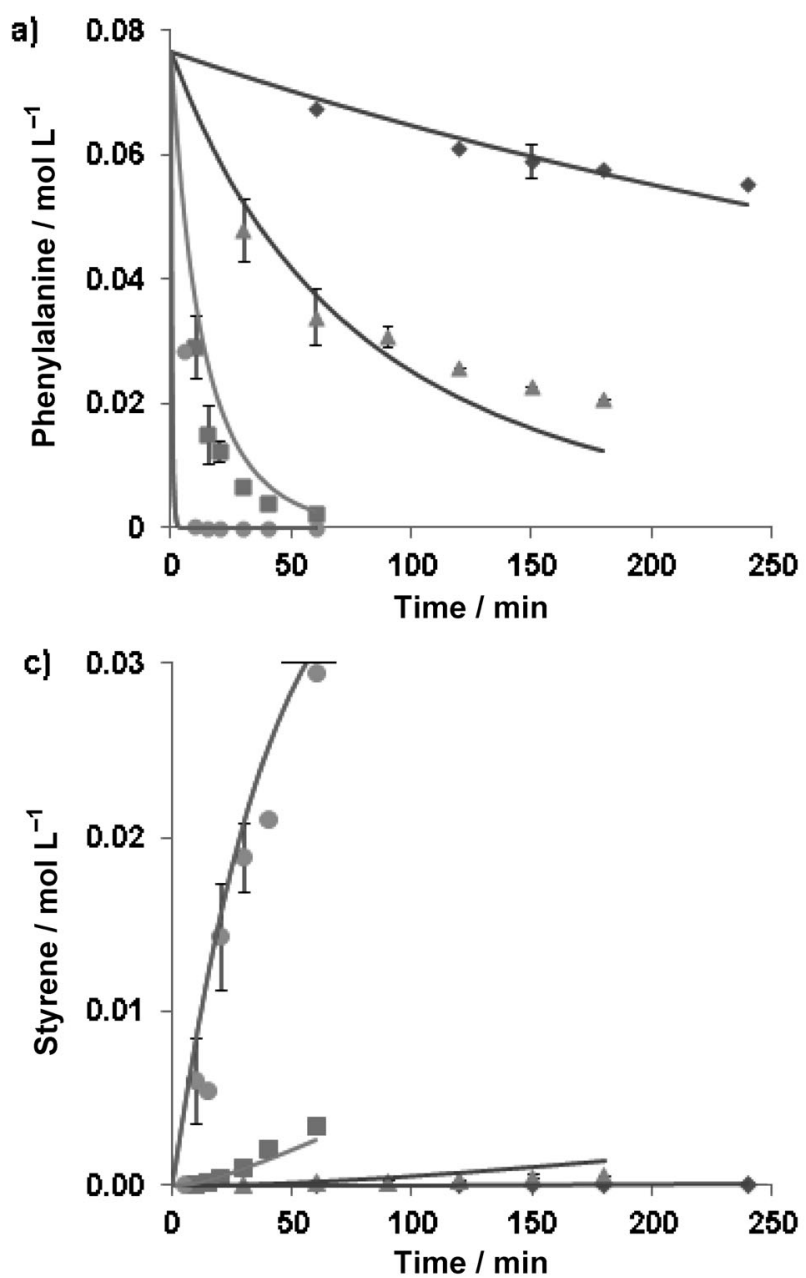
present in algae and the culture medium on the behavior of phenylalanine in HTW. This section presents these results.

Figure 3 a shows that addition of salts and boric acid generally increases the phenylalanine conversion. Comparing results from addition of the three sodium salts shows that $\mathrm{NaNO}_{3}$ has the greatest influence on phenylalanine conversion $(\approx 66 \%$ increase). Based on this observation, we speculate that perhaps nitrate has a more favorable interaction with phenylalanine or stabilizes the transition state better than chloride or sulfate. $\mathrm{KCl}$ increases the phenylalanine conversion less than $\mathrm{NaCl}$ although the uncertainty in the $\mathrm{KCl}$ result is higher. Mishima and Matsuyama ${ }^{[56]}$ attributed the higher activity of sodium salts
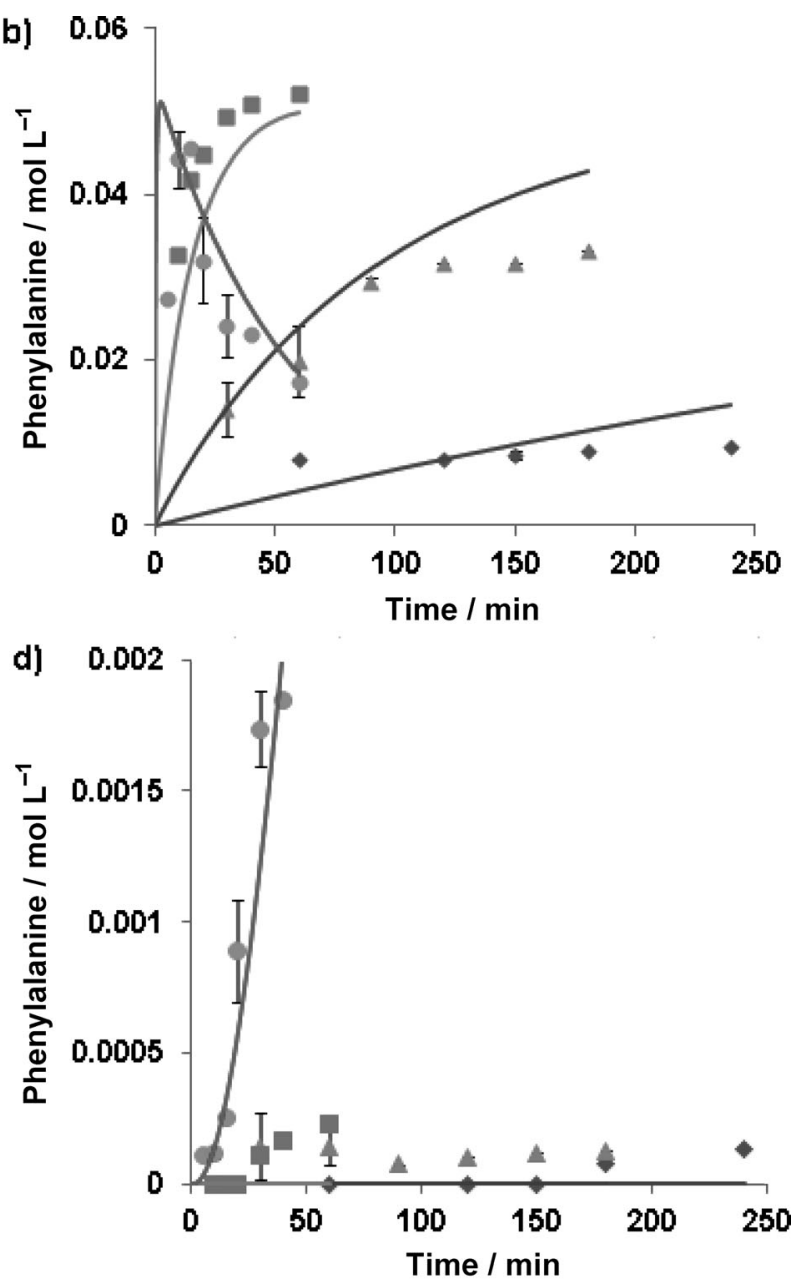

Figure 2. Comparison of experimental (discrete points) and model (smooth curves) results for a) phenylalanine, b) phenylethylamine, c) styrene, and d) phenylethanol at $\bullet 220, \boldsymbol{\Delta} 250, \mathbf{\square} 280$, and $\bullet 350^{\circ} \mathrm{C}$. 

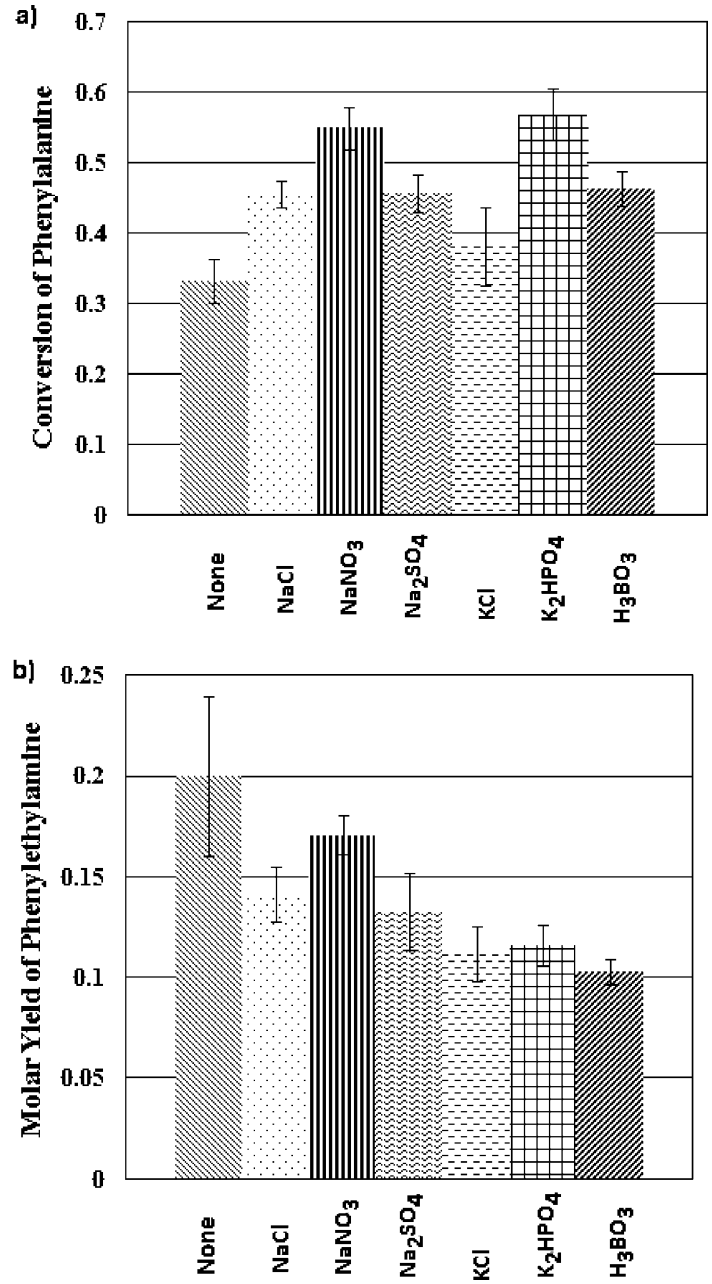

Figure 3. a) Phenylalanine conversion and b) phenylethylamine yield in the presence of salts and boric acid at $250^{\circ} \mathrm{C}$ and $30 \mathrm{~min}$ in HTW.

over potassium salts to the higher hydration enthalpy of $\mathrm{Na}^{+}$. The same phenomenon might be at work in the present system as well. $\mathrm{K}_{2} \mathrm{HPO}_{4}$ shows the most pronounced effect on phenylalanine conversion (increase of about $71 \%$ ), probably because of two divalent $\mathrm{K}^{+}$ions leading to greater interactions between the salt and phenylalanine. Lastly, $\mathrm{H}_{3} \mathrm{BO}_{3}$ increased the phenylalanine conversion only moderately (by around $40 \%)$.

One might expect that an increase in phenylalanine conversion would lead to a corresponding increase in the rate of decarboxylation, the major reaction path for phenylalanine reacting alone, thus increasing the yield of phenylethylamine. Figure $3 \mathrm{~b}$, however, shows that the yield of phenylethylamine decreases in the presence of each of the additives. $\mathrm{H}_{3} \mathrm{BO}_{3}$ and $\mathrm{KCl}$ provide the greatest decreases (about 49 and $45 \%$, respectively) compared to the case with no additive. $\mathrm{NaNO}_{3}$ induces the least decrease of about $15 \%$. These observations are in accord with the addition of $\mathrm{KCl}$ reportedly reducing the decarboxylation rate for $\alpha$-alanine. ${ }^{[28]}$ Those authors proposed the decrease to be due to either, 1) formation of a transition state less polar than the starting zwitterion of $\alpha$-alanine, or 2) formation of complexes of $\mathrm{K}^{+}$or $\mathrm{Cl}^{-}$with ionic sites of $\alpha$-alanine zwitterions, thereby reducing its ability to undergo decarboxylation.

The reaction network in Scheme 1 shows that phenylalanine can undergo two parallel primary reactions-decarboxylation or oligomerization. As the rate of decarboxylation decreases in the presence of salts (and boric acid), there must be an increase in the rate of the oligomer formation pathway. The carbon balances from the experiments with added salts were always lower than $70 \%$ (see the Supporting Information, Table 1), whereas without salt the carbon balance was around $90 \%$ under the same conditions. This result is consistent with an increase in the rate of formation of oligomers in presence of salts. LC-MS analysis of a sample from the reaction of phenylalanine in the presence of added $\mathrm{NaNO}_{3}$ confirmed the presence of high molecular weight compounds.

From the results and discussion above, we conclude that the salts examined here and boric acid inhibit decarboxylation but lead to an increase in high molecular weight compound formation from phenylalanine, thereby increasing phenylalanine conversion. This work is, to our knowledge, the first to report this effect of salts (or boric acid) on oligomerization of amino acids in HTW. It also reveals that these inorganic compounds could influence the relative rates of different reaction paths during hydrothermal liquefaction of algae.

\section{Binary mixtures of ethyl oleate and phenylalanine}

The previous sections characterized the products from phenylalanine alone in HTW and the effect of added salts and boric acid on the behavior of phenylalanine. This section examines the effect of an added organic molecule (ethyl oleate, which is a model compound for triglycerides in algae). The concentrations of ethyl oleate and phenylalanine were varied to mimic the broad range of triglyceride-to-protein ratios in different strains of algae. We carried out the reactions at $350^{\circ} \mathrm{C}$ as the yield of algal bio-oil is maximum at this temperature. ${ }^{[2]}$ The conversion of phenylalanine was always complete at this temperature, however, so we focus this discussion on the influence of added ethyl oleate on the yields and identities of products from phenylalanine. The effect of phenylalanine on ethyl oleate conversion and oleic acid yield is also explored. Note that a 0.2 molar ratio of ethyl oleate to phenylalanine would correspond to a 5.0 molar ratio of phenylalanine to ethyl oleate. The former will be considered to study the effects of ethyl oleate on phenylalanine and the later to explore the effects of phenylalanine on ethyl oleate.

As a control experiment, we examined phenylalanine alone in HTW (no ester added) at concentrations corresponding to those used in the mixtures (4000, 15000, and $22000 \mathrm{ppm}$ ). Similar yields of phenylethylamine and styrene were obtained for all three cases (see the Supporting Information, Table 2). These results indicate that the yields of phenylethylamine and styrene are independent of the phenylalanine concentration (as expected for a first-order reaction) and that any effects observed in the mixtures arise solely from the addition of ethyl oleate. 


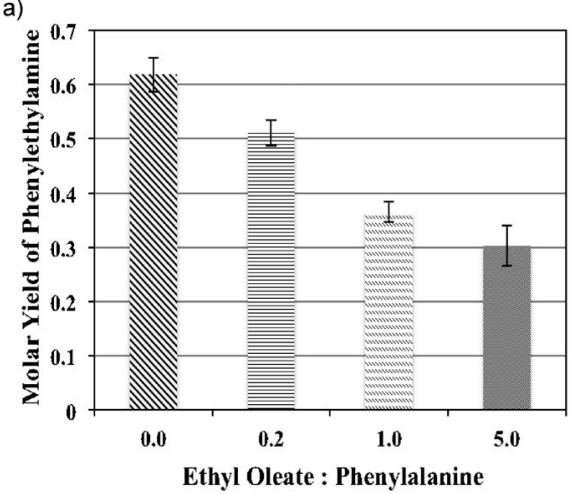

b)

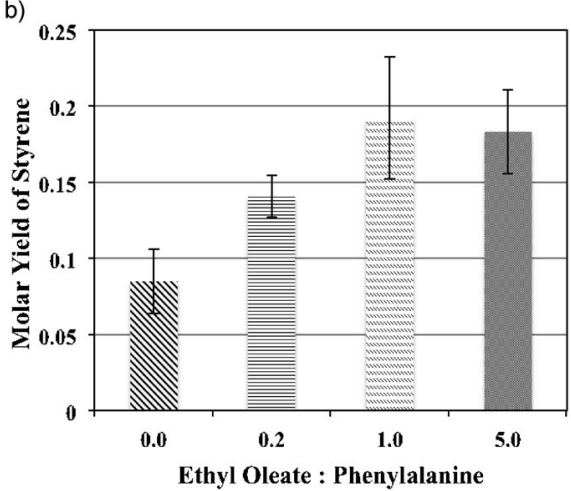

c)

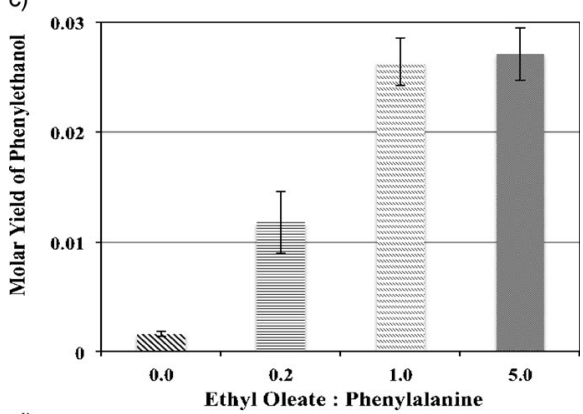

d)

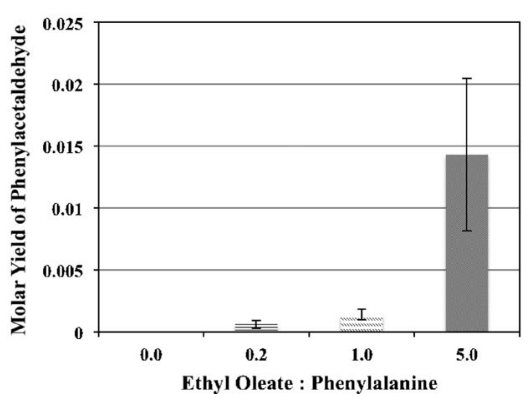

Figure 4. Molar yields of a) phenylethylamine, b) styrene, c) phenylethanol, and d) phenylacetaldehyde at $350^{\circ} \mathrm{C}$ and $10 \mathrm{~min}$ for different initial molar ratios of ethyl oleate to phenylalanine.

Tables 3 and 4 in the Supporting Information provide the yields of the various products at different batch holding times and the different initial molar ratios of ethyl oleate to phenylalanine. We present just a representative subset of that data in Figures 4-7. We remind the reader that the yields of phenylethylamine, styrene, and phenylethanol (Figure 4) are based on initial mols of phenylalanine loaded into the reactor, the yields of oleic acid (Figure 6) are based on initial mols of ethyl oleate loaded, and the yields of oleamides (Figure 7) are based on the initial mols of the limiting reactant loaded (either phenylalanine or ethyl oleate).

\section{Effect of ethyl oleate on phenylalanine}

First, we report and discuss the effect of added ethyl oleate on the products obtained from phenylalanine. Figure 4 a shows that the molar yield of phenylethylamine decreases from 0.62 without added ester to 0.30 as the initial ratio of ethyl oleate to phenylalanine in the binary mixture increases from 0.0 to 5.0. This behavior suggests faster reaction of phenylethylamine to form secondary products in the presence of ethyl oleate. To test the hypothesis of accelerated disappearance of phenylethylamine, we performed an experiment with $20 \mu \mathrm{L}$ of phenylethylamine, with and without $40 \mu \mathrm{L}$ of ethyl oleate, in water at $350^{\circ} \mathrm{C}$ for 10,20 , and $30 \mathrm{~min}$. This amount corresponds to a molar ratio of ethyl oleate to phenylethylamine equal to 0.7 .

Figure 5 shows that the conversion of phenylethylamine was always higher in the presence of ethyl oleate, thereby confirming that the disappearance of phenylethylamine is enhanced

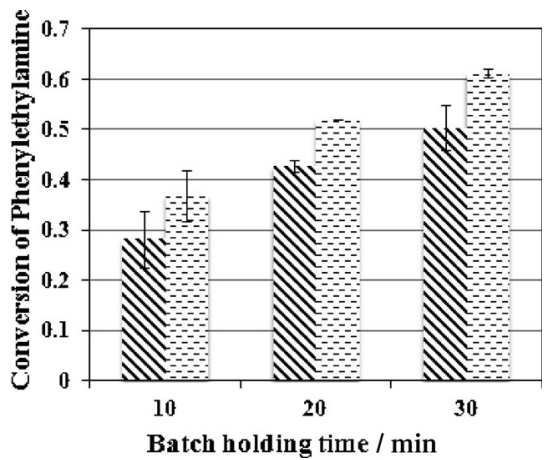

Figure 5. Conversion of phenylethylamine at $350^{\circ} \mathrm{C}$ and different batch holding times $\aleph$ without, $\because-$ with $40 \mu \mathrm{L}$ ethyl oleate $(0.7: 1$ molar ratio ethyl oleate to phenylalanine).

in the presence of ethyl oleate. For example, phenylethylamine conversion increased from 0.28 (without added ester) to 0.37 (in the presence of ester) at $10 \mathrm{~min}$, which is a net increase of $32 \%$. This increase in the conversion of phenylethylamine with added ester implies a corresponding decrease in its molar yield $(\approx 30 \%)$ when it is formed from phenylalanine with and without ethyl oleate ( 0.0 and 0.7 molar ratio). Interpolation of the data in Figure 4 a leads to an estimated molar yield of phenylethylamine of about 0.4 at an initial ethyl-oleate-to-phenylethylamine molar ratio of 0.7 . This value (0.4) is about $30 \%$ lower than the yield obtained without added ester, a relative decrease that is consistent with the results in Figure 5.

The increased conversion of phenylethylamine in the presence of ethyl oleate suggests an accompanying increase in the molar yield of styrene on increasing the amount of ester. Figure $4 \mathrm{~b}$ confirms this expectation. The molar yield of styrene at $10 \mathrm{~min}$ is 0.09 without any ester and around 0.19 when the molar ratio ethyl oleate to phenylalanine is 5.0. Similarly, Figure $4 \mathrm{c}$ shows that the molar yield of phenylethanol increases 
from 0.002 to 0.027 as the ethyl-oleate-to-phenylalanine ratio increases from 0.0 to 5.0. Thus, the addition of ethyl oleate enhances both deamination of phenylethylamine to styrene and hydration of styrene to phenylethanol.

These paths are accelerated upon addition of ethyl oleate because both deamination of organic compounds and hydration of styrene and other alkenes in an aqueous medium are acid-catalyzed reactions. ${ }^{[57-60]}$ The addition of ethyl oleate reduces the $\mathrm{pH}$ of the system due to the production of oleic acid from its hydrolysis, ${ }^{[8,9]}$ thereby catalyzing both the deamination and hydration reactions in the binary mixture.

In addition to altering the yields of products identified from the reaction of phenylalanine alone, addition of ethyl oleate also permitted quantification of a new product, phenylacetaldehyde. Figure $4 \mathrm{~d}$ shows that the molar yield of phenylacetaldehyde increases with an increase in the molar ratio of ethyl oleate to phenylalanine. The yield of phenylacetaldehyde also increases with an increase in the batch holding time at a given concentration ratio (see the Supporting Information Table 3). Klingler et al. ${ }^{[23]}$ have previously reported the formation of acetaldehyde from alanine via a lactic acid intermediate. A similar pathway could be at work here, wherein phenylalanine first forms phenyllactic acid via deamination, which then decarboxylates to form phenylacetaldehyde. The highest yield of phenylacetaldehyde was 0.04 , obtained from the reaction at the longest time $(60 \mathrm{~min})$ and most added ester (ethyl-oleate-tophenylalanine molar ratio of 5.0). Once again, it is likely that ethyl oleate catalyzes deamination of phenylalanine to form phenyllactic acid, subsequently forming phenylacetaldehyde under these conditions.

\section{Effect of phenylalanine on ethyl oleate}

Having discussed the results from these binary mixture experiments in terms of the influence of added ester on phenylalanine, we now examine the other side of the coin and discuss the influence of added phenylalanine on ethyl oleate. Figure $6 \mathrm{a}$ shows that the ethyl oleate conversion at $10 \mathrm{~min}$ is 0.49 without phenylalanine and 0.96 at a phenylalanine-toethyl-oleate molar ratio of 5.0. An increase in the amount of phenylalanine increases the conversion of ethyl oleate. This behavior is expected because ethyl oleate conversion is acid-catalyzed $^{[8,9]}$ and the presence of phenylalanine would reduce the initial $\mathrm{pH}$ of the solution [isoelectric point of phenylalanine is 5.3 at room temperature ${ }^{[29]}$ and an aqueous solution of phenylalanine (15000 ppm) has a $\mathrm{pH}$ of 5.9 at room temperature].

Higher conversion of ethyl oleate implies a corresponding increase in the yields of oleic acid, the major reaction product, which arises from hydrolysis. Figure $6 \mathrm{~b}$ offers confirmation as the yield of oleic acid at $10 \mathrm{~min}$ increases from 0.31 without phenylalanine to 0.78 at a phenylalanine-to-ethyl-oleate molar ratio of 5.0. At batch holding times greater than $10 \mathrm{~min}$, however, the molar yields of oleic acid show the opposite trend at a molar ratio of phenylalanine to ethyl oleate of 5.0 (see the Supporting Information, Tables 4 and 5). That is, at $60 \mathrm{~min}$ the oleic acid yield decreases from 0.73 without phenylalanine to 0.63 at a molar ratio of phenylalanine to ethyl oleate of 5.0 .
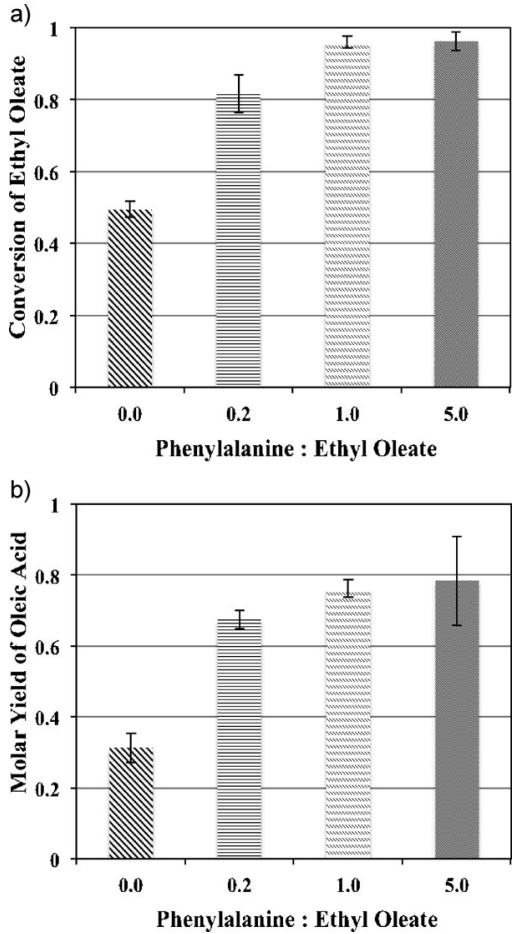

Figure 6. a) Conversion of ethyl oleate and b) yield of oleic acid at $350^{\circ} \mathrm{C}$ and $10 \mathrm{~min}$ for different initial molar ratios of phenylalanine to ethyl oleate.

As we show below, this observation is consistent with oleic acid undergoing secondary reactions in the presence of phenylalanine to form additional products.

Figure 1 in the Supporting Information, which shows the total ion chromatogram for a reaction at $350^{\circ} \mathrm{C}$ and $30 \mathrm{~min}$ with a phenylalanine-to-ethyl-oleate molar ratio of 1.0 , indicates the presence of three oleamides [9-octadecenamide (ODM), $\mathrm{N}$-ethyl-9-octadecenamide (EODM), and $\mathrm{N}$-phenylethyl9-octadecenamide (PEODM)]. Roe et al. ${ }^{[61]}$ mentioned previously that ODM can be formed in HTW by the reaction of oleic acid or ethyl oleate with ammonia. For the binary system of phenylalanine and ethyl oleate, ammonia is generated in situ during deamination of phenylethylamine to styrene. It is also possible in this environment for ODM to undergo condensation with ethanol (formed in small quantity during formation of ODM from ethyl oleate) and form EODM. ${ }^{[62]}$ Lastly, phenylethylamine could also react with oleic acid or ethyl oleate in a similar fashion to form PEODM (see reactions in the Supporting Information). These reactions would lead to a decrease in the yield of oleic acid, and this decrease would be expected to be most significant at longer times and in mixtures with more phenylalanine. Both of these expectations are consistent with the experimental results.

Figure $7 \mathrm{a}$ shows that the total yield of amides at $10 \mathrm{~min}$ is always about $16-20 \%$ of the theoretical maximum yield. The yield is not affected by different initial molar ratios of phenylalanine to ethyl oleate considering the experimental uncertainty. Similar results were obtained at other batch holding times (see the Supporting Information, Table 4). 


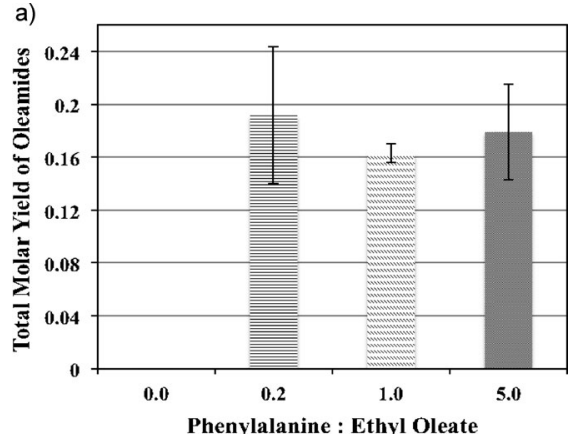

b)

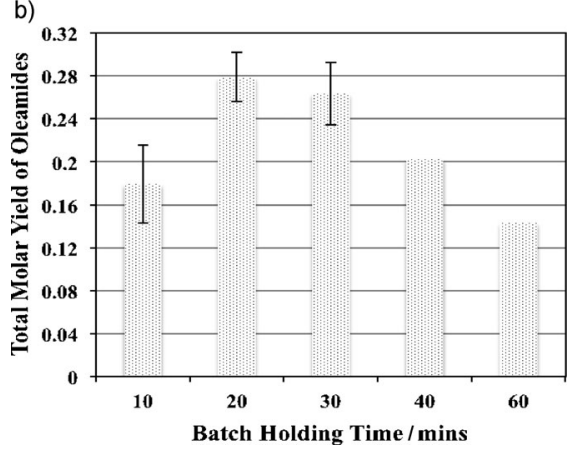

Figure 7. a) Total yield of amides at $350^{\circ} \mathrm{C}$ and $10 \mathrm{~min}$ for different initial molar ratios of phenylalanine to ethyl oleate and $b$ ) total yield of amide at various batch holding times and phenylalanine-to-ethyl-oleate molar ratio of 5.0.

Figure $7 \mathrm{~b}$ shows that, at a particular initial ratio of phenylalanine to ethyl oleate, the total yield of amides first increases and then decreases as the batch holding time is increased. Results obtained at the other molar ratios showed the same trend. Table 4 in the Supporting Information shows that the yield of PEODM is always higher than the yields of ODM or EODM and that the yield of PEODM first increases with time and then decreases, whereas the yields of ODM or EODM continually increase with time. These trends suggest that PEODM undergoes secondary decomposition. One possibility to account for these observations is deamidation of PEODM to styrene, as shown below. The octadecenamide group on PEODM $\left(\mathrm{C}_{17} \mathrm{H}_{33}-\mathrm{CO}-\mathrm{NH}-\right)$ is a better leaving group than the amino substituent $\left(-\mathrm{NH}_{2}\right)$ in phenylethylamine because the former anion is stabilized via conjugation with the carbonyl group. Therefore, PEODM can undergo deamidation to form styrene similar to the deamination of phenylethylamine, the latter path having being demonstrated in our work. Deamidation could be another reason why the yields of ODM (see the Supporting Information, Table 4) and styrene (Figure 4 b) increase at longer batch holding times for the binary mixture (Scheme 2).

Along with deamidation, hydrolysis is another potential pathway for PEODM degradation. Duan et al. ${ }^{[63]}$ reported that
$\mathrm{N}$-substituted amides hydrolyze to give the corresponding amine and carboxylic acid. This reaction is reversible and follows first-order kinetics. Thus, there exists a possibility of hydrolysis of PEODM to form phenylethylamine and oleic acid under our conditions. Hydrolysis of PEODM would be favored as more PEODM is formed at higher batch holding times, thus accounting for a net decrease in total yield of amides.

Brown et al. ${ }^{[2]}$ and Valdez et al. ${ }^{[64]}$ have characterized and quantified fatty acid amides as products from the hydrothermal liquefaction of algae. Valdez et al. ${ }^{[64]}$ reported that the yields of palmitic acid amide varied from 0.5 to $3\left(\mathrm{mg} \mathrm{g}^{-1}\right.$ of dry algae) depending on whether hexane or hexadecane was used, respectively, for recovery of bio-oil. However, these authors have only proposed the reaction of fatty acids with ammonia to account for the amide formation, neglecting the possibilities of amines reacting with fatty acids. The present work offers this new possibility.

Based on the above discussion and results, we propose the modified reaction network in Scheme 3 to account for the reactions that occur in a binary mixture of phenylalanine and ethyl oleate.

We sought to verify that this network could quantitatively account for the effect of addition of ethyl oleate on phenylalanine. Thus, we used the system of differential equations implied by this network [Eqs. (9)-(13)] and the methodology of optimization outlined earlier to fit the data from the mixture experiments.

$$
\begin{aligned}
& \frac{\mathrm{d} C_{\mathrm{PA}}}{\mathrm{d} t}=k_{1} C_{\mathrm{PA}}-k_{4} C_{\mathrm{PA}}^{2} \\
& \frac{\mathrm{d} C_{\mathrm{PEA}}}{\mathrm{d} t}=k_{1} C_{\mathrm{PA}}-k_{2} C_{\mathrm{PEA}}-k_{7} C_{\mathrm{PEA}}+k_{9} C_{\mathrm{PEODM}} \\
& \frac{\mathrm{d} C_{\mathrm{STY}}}{\mathrm{d} t}=k_{2} C_{\mathrm{PEA}}-k_{3} C_{\mathrm{STY}}-k_{5} C_{\mathrm{STY}}+k_{6} C_{\mathrm{PEOH}}+k_{8} C_{\mathrm{PEODM}} \\
& \frac{\mathrm{d} C_{\mathrm{PEOH}}}{\mathrm{d} t}=k_{3} C_{\mathrm{STY}}-k_{6} C_{\mathrm{PEOH}} \\
& \frac{\mathrm{d} C_{\mathrm{PEODM}}}{\mathrm{d} t}=k_{7} C_{\mathrm{PEA}}-k_{8} C_{\mathrm{PEODM}}-k_{9} C_{\mathrm{PEODM}}
\end{aligned}
$$

Table 5 compares the values of the rate constants obtained for the different pathways in the reaction network for different ratios of ester to phenylalanine. Note that the rate for formation of PEODM $\left(k_{7}\right)$ is taken to be first-order in phenylethylamine, but zero order with respect to oleic acid. This approximation simplified the modeling and allowed us to maintain focus on the pathways for phenylalanine. The model fits the temporal variation of the experimental product concentrations very well at all of the molar ratios explored for the binary mix-

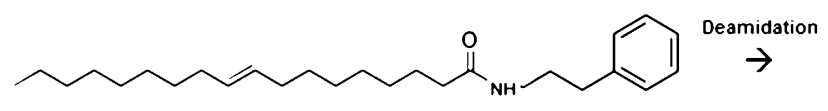

N-Phenylethyl-9-Octadecenamide

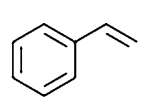

Styrene<smiles>CCCCCCCCC=CCCCCCCCC(N)=O</smiles>

9-Octadecenamide

Scheme 2. Deamidation of PEODM to styrene and ODM. 


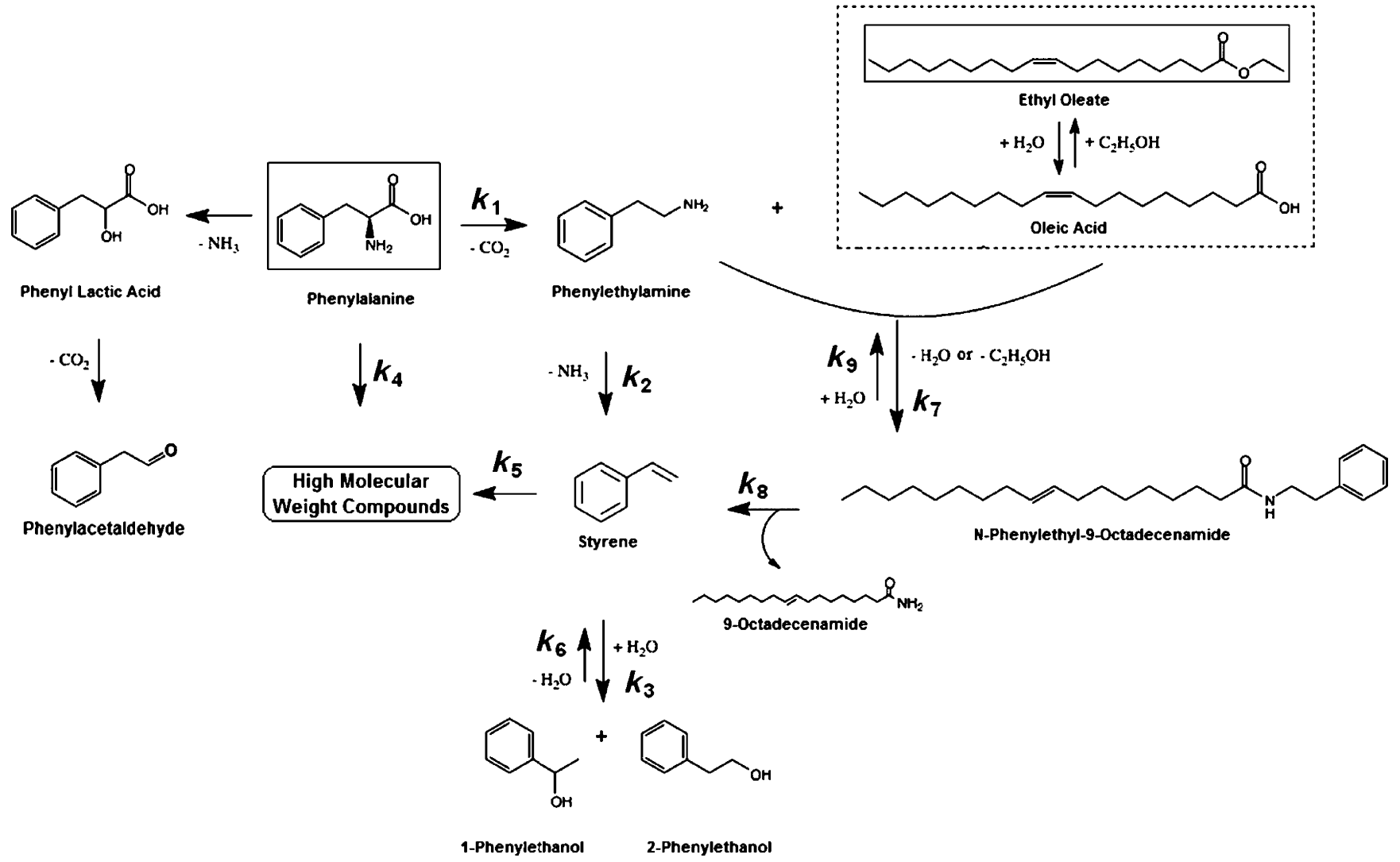

Scheme 3. Reaction network for a binary mixture of ethyl oleate and phenylalanine in HTW.

\begin{tabular}{|llllll|}
\hline \multicolumn{5}{|l|}{ Table 5. Rate constants at $350^{\circ} \mathrm{C}$ for different initial ratios of ester to phenylalanine. } \\
$\begin{array}{l}\text { Rate constant }(k) \\
\text { in Scheme } 3\end{array}$ & Units & \multicolumn{5}{c}{ Initial ratio of ethyl oleate to phenylalanine } \\
\hline 1 & & 0 & 0.2 & 1.0 & 5.0 \\
\hline & $\mathrm{min}^{-1}$ & 1.65 & 1.91 & 2.02 & 2.22 \\
3 & $\mathrm{~min}^{-1}$ & 0.018 & 0.029 & 0.035 & 0.043 \\
4 & $\mathrm{~min}^{-1}$ & 0.004 & 0.013 & 0.018 & 0.023 \\
5 & $\mathrm{Lmol}^{-1} \mathrm{~min}^{-1}$ & 11.62 & 12.07 & 11.25 & 12.75 \\
6 & $\mathrm{~min}^{-1}$ & 0.0002 & 0.0016 & 0.0131 & 0.0217 \\
7 & $\mathrm{~min}^{-1}$ & 0.0006 & 0.0920 & 0.1024 & 0.1316 \\
8 & $\mathrm{~min}^{-1}$ & - & 0.0084 & 0.0379 & 0.0501 \\
9 & $\mathrm{~min}^{-1}$ & - & 0.0375 & 0.0340 & 0.0361 \\
& $\mathrm{~min}^{-1}$ & - & 0.0431 & 0.0413 & 0.0391 \\
\hline
\end{tabular}

ture of phenylalanine and ethyl oleate as is seen in the parity plot in Figure 8 and in the Supporting Information, Scheme 1.

Table 5 shows that the decarboxylation rate constant $k_{1}$ increases by $35 \%$ at the highest molar ratio. $\mathrm{Li}$ and Brill ${ }^{[29]}$ reported that the rate constant for decarboxylation of phenylalanine nearly doubled as the $\mathrm{pH}$ decreased from 5.3 to 2.5 (at $330^{\circ} \mathrm{C}$ ). A similar effect of $\mathrm{pH}$ could be at work in this binary system, as more oleic acid would be generated at the higher ester concentrations, thereby lowering the $\mathrm{pH}$ of the solution.

The addition of ester has an even more marked effect on the rate constants $k_{2}$ and $k_{3}$ (increasing by 140 and $530 \%$, respectively, at the highest molar

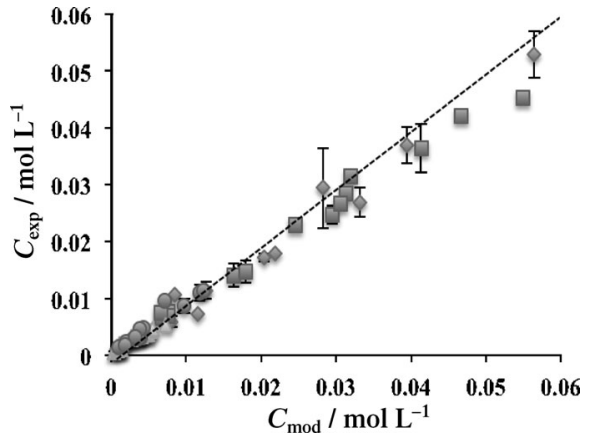

Figure 8. Parity plot of experimental and model concentrations for $\bullet$ phenylethylamine, $\mathbf{m}$ styrene, $\boldsymbol{\Delta}$ phenylethanol, and $\bullet N$-phenylethyl-9-octadecenamide for binary mixture at $350^{\circ} \mathrm{C}$ and different batch holding times. ratio of 5.0), as deamination of phenylethylamine to styrene and hydration of styrene to phenylethanol is enhanced upon adding ester. The rate constant for oligomerization of phenylalanine $\left(k_{4}\right)$ is independent of added ester, suggesting that the rate of this path is not $\mathrm{pH}$ dependent. However, the rate constant for styrene conversion to high molecular weight compounds $\left(k_{5}\right)$ increases by two orders of magnitude as more ester is added, probably because of enhanced acid catalysis at the higher ethyl oleate concentrations. Dimers of styrene (1,3diphenylbutane) were identified in the GC analysis but not quantified (see the Supporting Information, Figure 1). Lastly, the dehydration of phenylethanol is increased nearly 230-times in the presence of ethyl oleate at a molar ratio of phenylalanine to ethyl oleate of 5.0. Once again, the acidic environment 
(in the presence of fatty acid from ester hydrolysis) would be favorable for dehydration of alcohols as has been previously reported. ${ }^{[52-54]}$ The rate constant for formation of PEODM $\left(k_{7}\right)$ increases by an order of magnitude as the ethyl-oleate-to-phenylalanine molar ratio increases from 0.2 to 5.0, but this increase can probably be attributed to the model not explicitly accounting for the higher oleic acid concentrations present at the higher ratios. The rate constant for formation of styrene from PEODM $\left(k_{8}\right)$ and that for hydrolysis of PEODM $\left(k_{9}\right)$ does not change significantly with change in ester concentration, suggesting that they are not affected by a change in the $\mathrm{pH}$. For instance, Duan et al. ${ }^{[63]}$ have shown that the rate of hydrolysis of $\mathrm{N}$-methylacetamide is increased at a low $\mathrm{pH}(<2)$, but remains constant at near-neutral $\mathrm{pH}$.

\section{Implications for hydrothermal liquefaction of algae}

The results from this study of phenylalanine reactions in HTW have several implications for hydrothermal liquefaction of algae. Several products identified in bio-oil from algae could have originated from amino acids within the proteins in the cells. Crude bio-oil obtained during algae liquefaction contains amines, which can be formed via decarboxylation of amino acids. Bio-oil also contains high molecular weight compounds, which can arise due to oligomerization during the reaction of amino acids in HTW.

Secondly, the phenylalanine pathway to oligomerized products can be important at the temperatures at which hydrothermal liquefaction of algae is carried out, for example, $350^{\circ} \mathrm{C}$. This path following second-order kinetics implies that oligomerization will become more significant at higher concentrations (higher biomass loadings). Oligomerization products can also arise from styrene, which contains a vinyl group permitting it to undergo addition reactions to form dimers and trimers. One strategy to reduce the rate of oligomerization is to hydrogenate the double bond in styrene when it is formed. Thus, one might anticipate that algae liquefaction in the presence of a known hydrogenation catalyst and $\mathrm{H}_{2}$ might produce a biooil with less of a high molecular weight component, as demonstrated by Duan and Savage. ${ }^{[12]}$ Oligomerization occurring with phenylalanine or other amino acids is difficult to control. Some strategies that can be used to reduce oligomerization are to use a chain-terminating molecule that can reduce the possibility of this type of step polymerization or perform liquefaction at lower temperatures or lower biomass loadings.

We have discovered that salts and boric acid accelerate phenylalanine conversion but decrease the yield of phenylethylamine and increase the yield of oligomers. Salts are present in $5-15$ wt \% in dry algae. It seems that their presence in algae can lead to undesirable oligomer formation from proteins and reduce the quality of bio-oil obtained from algae.

Lastly, the binary mixture of ethyl oleate and phenylalanine gave valuable insights for the reactions of complex systems such as triglycerides and proteins. The rate of deamination of phenyethylalmine to styrene increases in the presence of ester. Deamination liberates ammonia, which can react with fatty acids/esters to form amides. Similarly, phenylethylamine can react with fatty acids/esters to form the corresponding amides, which could potentially produce additional styrene at higher temperatures or longer batch holding times. The amide formation is undesirable as it adds to the nitrogen content in the bio-oil and decreases the fatty acid yields.

\section{Conclusions}

Under the conditions studied, phenylalanine readily underwent decarboxylation to form phenylethylamine. Subsequently, phenylethylamine underwent deamination to styrene (favored at high temperatures), and styrene underwent either hydration to form phenylethanol or oligomerization. Phenylethanol can dehydrate to a small extent in high-temperature water (HTW) to styrene. Phenylalanine can also oligomerize at high temperatures and longer batch holding times.

We propose a reaction network based on the above observations. A phenomenological kinetics model based on the proposed network accurately describes the trends in the data and typically estimates the concentrations of the reactant and products within their experimental errors. The rate constant for phenylethylamine formation is largest amongst all the firstorder rate constants. Thus, we elucidate broadly through this study of phenylalanine that many different types of reactions (e.g., decarboxylation, hydration, oligomerization, and dehydration) occur during hydrothermal liquefaction of algae.

Experiments that explored the effects of salts and boric acid on the rate of decarboxylation of phenylalanine revealed that $\mathrm{NaNO}_{3}$ and $\mathrm{K}_{2} \mathrm{HPO}_{4}$ have the most influence on phenylalanine conversion. However, the phenylethylamine yield and the carbon balance both decrease, indicating that oligomerization is favored in the presence of salts.

Mixtures of ethyl oleate and phenylalanine showed several interesting results. As the concentration of ethyl oleate increases, deamination of phenylethylamine and hydration of styrene are increasingly favored. Thus, the yield of phenylethylamine decreases and those of styrene and phenylethanol increase with increasing ester amount. As the amount of ester increases, phenylalanine also undergoes deamination, as a parallel reaction, to form phenylacetaldehyde, possibly favored due to lowering of the $\mathrm{pH}$. Conversely, as the relative amount of phenylalanine is increased, the conversion of ethyl oleate and yield of oleic acid increased. New reaction products (9-octadecenamide, $\mathrm{N}$-ethyl-9-octadecenamide, and $\mathrm{N}$-phenylethyl-9-octadecenamide) are also formed in the binary mixture due to the interaction of phenylethylamine/ammonia with ethyl oleate/oleic acid. The total yield of the amides remains similar with changing molar ratios of the binary components. Due to the formation of these amides, the yields of oleic acid and phenylethylamine decreases at longer times.

A modified reaction network is proposed for the binary mixture, and the rate constants for this network were compared at different ratios of ethyl oleate to phenylalanine. Increasing the relative amount of ester led to higher rate constants for decarboxylation of phenylalanine, deamination of phenylethylamine, and hydration of styrene. The rate constant for dehydration of phenylethanol also increases by two orders of magnitude as 
compared to its value with no ester added. The proposed network for the binary mixture accurately describes the trends in the data and typically estimates the concentrations of different products within their experimental errors.

The study of phenylalanine in HTW has implications to algae liquefaction. For instance, at $350^{\circ} \mathrm{C}$, when the bio-oil yield from algae is maximum, we obtain a low carbon balance, indicating oligomer formation. Ideally, one would want to avoid the formation of these oligomers to improve the quality of bio-oil. Strategies that involve hydrogenation of olefins in biocrude or their cracking to smaller compounds might enhance bio-oil yields. Salts also enhance oligomer formation, whereas esters can form undesirable amides, which can increase the nitrogen content in the crude bio-oil.

\section{Experimental Section}

We carried out all experiments in batch reactors assembled from 3/8 inch 316 stainless steel Swagelok tube fittings (one port connector and two caps). Each reactor had an internal volume of approximately $1.5 \mathrm{~cm}^{3}$. Prior to using these reactors, we filled them with water and heated them in a fluidized sand bath at $300^{\circ} \mathrm{C}$ for $60 \mathrm{~min}$ to remove any residual materials and expose the reactor walls to the HTW environment.

All chemicals were purchased from either Sigma Aldrich or Fischer Scientific in high purity $(\geq 99 \%)$ and used as received. The water was distilled and deionized prior to use.

Prior to loading the reactors, we prepared a stock solution by dissolving phenylalanine $(1.5 \mathrm{~g})$ in water $(100 \mathrm{~mL}$; giving a concentration of $15000 \mathrm{ppm}$ ). Fresh stock solutions were prepared every two weeks. The reactors were then loaded at room temperature with suitable amounts of the stock solution. The amount of stock solution loaded for each experiment was such that the liquid phase would occupy about $95 \%$ of the reactor volume at the reaction conditions, based on the density of pure water at the same conditions, (i.e., 1.20, 1.14, 1.08, and $0.92 \mathrm{~mL}$ was loaded at 220, 250,280 or $350^{\circ} \mathrm{C}$, respectively). Note that concentrations were calculated based on this volume throughout this report. Pressure at reaction conditions could be determined from the saturated steam tables as $2.3,4.0,6.4$, and $17.0 \mathrm{MPa}$ at $220,250,280$, or $350^{\circ} \mathrm{C}$, respectively. The loaded reactors were sealed and placed in a preheated, fluidized sand bath (Techne SBL-2D) and maintained at the desired temperature using a temperature controller (Techne TC$8 \mathrm{D})$. The sand bath was isothermal within $\pm 1{ }^{\circ} \mathrm{C}$. The reactor heatup time was $2-3 \mathrm{~min}$ as measured previously, ${ }_{1}^{[8]}$ which is short relative to the typical batch holding times used in this study. Upon reaching the desired batch holding time, the reactors were removed from the sand bath and quenched by immersing them in a cold water bath. The reactors were opened and the contents were recovered using methanol, which was able to dissolve both the reactants and the products formed during the reaction, thereby giving a clear homogeneous phase for further analysis.

We also performed experiments with the addition of various salts $\left(\mathrm{NaCl}, \mathrm{NaNO}_{3}, \mathrm{Na}_{2} \mathrm{SO}_{4}, \mathrm{KCl}, \mathrm{K}_{2} \mathrm{HPO}_{4}\right)$ and boric acid $\left(\mathrm{H}_{3} \mathrm{BO}_{3}\right)$, at $250^{\circ} \mathrm{C}$ and $30 \mathrm{~min}$. Stock solutions were prepared by dissolving a salt (or boric acid; $40 \mathrm{mg}$, ) in the phenylalanine stock solution $(10 \mathrm{~mL})$. The concentration of each additive in the phenylalanine solution was $4000 \mathrm{mg} \mathrm{L}^{-1}$. The concentration of salt was chosen such that the ratio of salt to phenylalanine was between $20-25 \%$ $(w / w)$, which is a typical ratio of ash/proteins in algae. ${ }^{[2]}$
Reactions of a binary mixture were performed at $350^{\circ} \mathrm{C}(10,20,30$, 40 , and $60 \mathrm{~min})$ at three different molar ratios of phenylalanine to ethyl oleate $(\approx 0.2: 1 ; \approx 1: 1$; and $\approx 5: 1)$. Depending on the desired molar ratio of phenylalanine to ethyl oleate, we added stock solution $(0.92 \mathrm{~mL}$; either 4000,15000 , or $22000 \mathrm{ppm})$ along with the corresponding amount of ethyl oleate (either 10 or $40 \mu \mathrm{L}$ ) to the reactor. Phenylalanine stock solution was prepared fresh for each mixture.

We performed control experiments at room temperature to determine the recovery of phenylalanine in the absence and presence of salt $\left(\mathrm{K}_{2} \mathrm{HPO}_{4}\right)$. We loaded different stock solutions $(1 \mathrm{~mL})$ into a reactor and then sealed the reactor. The reactors were placed in the fluidized sand bath at $22.5 \pm 1{ }^{\circ} \mathrm{C}$ for $30 \mathrm{~min}$. The post-reaction work-up procedure used for the experiments at the elevated temperatures was then performed.

To quantify phenylalanine, we used high pressure liquid chromatography (HPLC) in combination with a UV detector. A Zorbax ODS column ( $4.6 \mathrm{~mm}$ inner diameter $\times 250 \mathrm{~mm}$ length) with $5 \mu \mathrm{m}$ particle size was used for the separation of phenylalanine. An isocratic method using a mobile phase consisting of water $(90 \%)$ containing trifluoroacetic acid $(0.1 \%)$ and acetonitrile $(10 \%)$ containing trifluoroacetic acid ( $0.1 \%)$ was used at $1 \mathrm{~mL} \mathrm{~min}^{-1}$ for a total runtime of $20 \mathrm{~min}$. The phenylalanine peak eluted at about $7 \mathrm{~min}$ and had a maximum absorbance at $205 \mathrm{~nm}$.

We used an Agilent Technologies model $6890 \mathrm{~N}$ gas chromatograph (GC) equipped with an autosampler, autoinjector, and mass spectrometric detector to identify the main products from the HTW treatment of phenylalanine and binary mixtures. Phenylalanine was not amenable to GC analysis due to very poor peak resolution on the GC. A Wiley mass spectral library was used for compound identification by matching the mass fragments of observed peaks with those in the library. An Agilent Technologies model 6890 GC equipped with a flame ionization detector (FID) was used to quantify the products. The reaction products were separated on a HP$5 \mathrm{MS}$ fused silica, non-polar capillary column (50 m length $\times$ $0.20 \mathrm{~mm}$ inner diameter $\times 0.33 \mu \mathrm{m}$ film thickness). We used an inlet temperature of $300^{\circ} \mathrm{C}$, a split ratio of $5: 1$, and an injection volume of $1.0 \mu \mathrm{L}$. The temperature program involved an initial oven temperature of $40^{\circ} \mathrm{C}$ followed by heating to $150^{\circ} \mathrm{C}$ at a rate of $10^{\circ} \mathrm{Cmin}^{-1}$ (isothermal for $4 \mathrm{~min}$ ), then ramping at $10^{\circ} \mathrm{Cmin}^{-1}$ to $225^{\circ} \mathrm{C}$ (isothermal for $5 \mathrm{~min}$ ), and a final ramp of $10^{\circ} \mathrm{Cmin}^{-1}$ to $300^{\circ} \mathrm{C}$ (isothermal for $15 \mathrm{~min}$ ), giving a total run time of $50 \mathrm{~min}$. Helium served as the carrier gas $\left(1 \mathrm{~mL} \mathrm{~min}^{-1}\right)$.

To detect high molecular weight compounds and oligomers of phenylalanine in the product mixture, a Agilent Q-TOF LC-MS system equipped with an Agilent 1290 binary pump was used. Agilent Zorbax Eclipse Plus C-18 column $(2.1 \times 50 \mathrm{~mm}, 1.8 \mu \mathrm{m}$ particle size) was used as stationary phase. One Solvent (A) comprised water with formic acid $(0.1 \%)$. Another solvent (B) comprised acetonitrile $(95 \%)$, water $(5 \%)$, and formic acid $(0.1 \%)$. A gradient method starting with $5 \%$ solvent $B$ (hold $1 \mathrm{~min}$ ) transitioning to $100 \%$ B over $9 \mathrm{~min}$ (hold $2 \mathrm{~min}$ ) was used. The flow rate to the column was maintained at $0.4 \mathrm{~mL} \mathrm{~min}^{-1}$. Representative samples from reactions conducted at $250^{\circ} \mathrm{C}$ and $30 \mathrm{~min}$ and $350^{\circ} \mathrm{C}$ and $60 \mathrm{~min}$ were analyzed. These samples were recovered in a 1:1 $(\mathrm{v} / \mathrm{v})$ mixture of methanol and chloroform (to give a homogenous phase with water) and diluted to $10 \mathrm{~mL}$ to ensure that all the oligomers are soluble in the chloroform phase.

Lastly, ethyl oleate and oleic acid were quantified by using an Agilent Technologies model 7890N GC-FID. The separation was carried out on a DB-FFAP column ( $30 \mathrm{~m}$ length $\times 0.32 \mathrm{~mm}$ inner diameter $\times$ $0.25 \mu \mathrm{m}$ film thickness). The inlet temperature was set at $220^{\circ} \mathrm{C}$ with a split ratio of 5:1 and an injection volume of $1.0 \mu \mathrm{L}$. The tem- 
perature program involved an initial oven temperature of $50^{\circ} \mathrm{C}$ followed by heating to $120^{\circ} \mathrm{C}$ at a rate of $5^{\circ} \mathrm{Cmin}^{-1}$ and ramping at $20^{\circ} \mathrm{C}$ to $220^{\circ} \mathrm{C}$ (isothermal for $6 \mathrm{~min}$ ), giving a total run time of $25 \mathrm{~min}$. Helium served as the carrier gas $\left(1 \mathrm{~mL} \mathrm{~min}^{-1}\right)$.

We generated calibration curves using standards of pure phenylalanine, phenylethylamine, styrene, phenylethanol, ethyl oleate, and oleic acid to determine the corresponding concentrations of each of these compounds. Product molar yields were calculated by dividing the number of mols of the product by the number of mols of limiting reactant initially loaded into the reactor. Selected experiments at each temperature, all experiments with salts (or boric acid), and selected experiments with binary mixtures of phenylalanine and ethyl oleate were conducted in triplicate. Experimental uncertainty was calculated as the standard deviations in the product yields from these replicated experiments.

\section{Acknowledgements}

We thank Prof. Adam Matzger for his insights regarding the reaction chemistry, Mr. James Windak for assistance in running the LC-MS analyses, and Apurva Lingnurkar for completing some of the binary mixture experiments. We gratefully acknowledge the financial support received from NSF Grant-EFRI 0937992 to carry out this work.

Keywords: algae $\cdot$ high temperature chemistry $\cdot$ kinetics phenylalanine $\cdot$ water chemistry

[1] J. A. V. Costa, M. G. de Morais, Bioresour. Technol. 2011, 102, 2-9.

[2] T. M. Brown, P. Duan, P. E. Savage, Energy Fuels 2010, 24, 3639-3646

[3] T. M. Mata, A. A. Martins, N. S. Caetano, Renewable Sustainable Energy Rev. 2010, 14, 217-232.

[4] R. B. Levine, T. Pinnarat, P. E. Savage, Energy Fuels 2010, 24, 5235-5243.

[5] S. M. Heilmann, H. T. Davis, L. R. Jader, P. A. Lefebvre, M. J. Sadowsky, F. J. Schendel, M. G. V. Keitz, K. J. Valentas, Biomass Bioenergy 2010, 34 $875-882$.

[6] Q. Guan, P. E. Savage, J. Supercrit. Fluids 2012, 61, 139-145.

[7] P. E. Savage, Chem. Rev. 1999, 99, 603-621.

[8] S. Changi, T. Pinnarat, P. E. Savage, Ind. Eng. Chem. Res. 2011, 50, $3206-$ 3211.

[9] S. Changi, T. Pinnarat, P. E. Savage, Ind. Eng. Chem. Res. 2011, 50, $12471-12478$.

[10] S. Changi, T. M. Brown, P. E. Savage, Chem. Eng. J. 2012, 189, 336-345 .

[11] E. W. Becker, Biotechnol. Adv. 2007, 25, 207-210.

[12] P. Duan, P. E. Savage, Ind. Eng. Chem. Res. 2011, 50, 52-61.

[13] D. Zhou, L. Zhang, S. Zhang, H. Fu, J. Chen, Energy Fuels 2010, 24 4054-4061.

[14] Y. J. Bae, C. Ryu, J. Jeon, J. Park, D. J. Suh, Y. Suh, D. Chang, Y. Park, Bioresour. Technol. 2011, 102, 3512-3520.

[15] P. Biller, A. B. Ross, Bioresour. Technol. 2011, 102, 215-225.

[16] H. Hwang, T. G. Hartman, C. Ho, J. Agric. Food Chem. 1995, 43, $2917-$ 2921.

[17] J. R. Vallentyne, Geochim. Cosmochim. Acta 1964, 28, 157-188.

[18] Y. Qian, M. H. Engel, S. A. Macko, S. Carpenter, J. Deming, Geochim. Cosmochim. Acta 1993, 57, $3281-3293$.

[19] E. Andersson, N. Holm, Orig. Life Evol. Biosph. 2000, 30, 9-23.

[20] J. L. Bada, S. L. Miller, N. Zhao, Orig. Life Evol. Biosph. 1995, 25, 111- 118.

[21] H. C. Helgeson, J. P. Amend, Thermochim. Acta 1994, 245, 89-119.

[22] N. Sato, A. T. Quintain, K. Kang, H. Daimon, K. Fujie, Ind. Eng. Chem. Res. 2004, 43, 3217-3222.

[23] D. Klingler, J. Berg, H. Vogel, J. Supercrit. Fluids 2007, 43, 112-119.

[24] J. S. Cox, T. M. Seward, Geochim. Cosmochim. Acta 2007, 71, 2264-2284.
[25] W. Abdelmoez, T. Nakahasi, H. Yoshida, Ind. Eng. Chem. Res. 2007, 46, $5286-5294$.

[26] W. Abdelmoez, H. Yoshida, T. Nakahasi, Int. J. Chem. React. Eng. 2010, 8 , DOI:10.2202/1542-6580.1903.

[27] M. Faisal, N. Sato, A. T. Quintain, H. Daimon, K. Fujie, Int. J. Chem. Kinet 2007, 39, 175-180.

[28] J. Li, X. Wang, M. T. Klein, T. B. Brill, Int. J. Chem. Kinet. 2002, 34, 271 277.

[29] J. Li, T. B. Brill, J. Phys. Chem. A 2003, 107, 5987-5992.

[30] J. Li, T. B. Brill, Int. J. Chem. Kinet. 2003, 35, 602-610.

[31] Y. Ogata, E. Imai, H. Honda, K. Hatori, K. Matsuno, Origins Life Evol. Biosphere 2000, 30, 527-537.

[32] D. K. Alargov, S. Deguchi, K. Tsujii, K. Horikoshi, Origins Life Evol. Biosphere 2002, 32, 1-12.

[33] Md. N. Islam, T. Kaneko, K. Kobayashi, Bull. Chem. Soc. Jpn. 2003, 76, $1171-1178$.

[34] T. Otake, T. Taniguchi, Y. Furukawa, F. Kawamura, H. Nakazawa, T. Kakegawa, Astrobiology 2011, 11, 799-813.

[35] K. Sakata, N. Kitadai, T. Yokoyama, Geochim. Cosmochim. Acta 2010, 74, $6841-6851$.

[36] A. G. Day, D. Brinkmann, S. Franklin, K. Espina, G. Rudenko, A. Roberst, K. S. Howse, Regul. Toxicol. Pharmacol. 2009, 55, 166-180.

[37] D. Xu, S. Wang, X. Hu, C. Chen, Q. Zhang, Y. Gong, Int. J. Hydrogen Energy 2009, 34, 5357-5364.

[38] O. T. Onsager, M. S. A. Brownrigg, R. Lødeng, Int. J. Hydrogen Energy $1996,21,883-885$.

[39] A. A. Peterson, F. Vogel, R. P. Lachance, M. Fröling, M. J. Antal Jr., J. W. Tester, Energy Environ. Sci. 2008, 1, 32-65.

[40] A. Kruse, E. Dinjus, Z. Phys. Chem. 2005, 219, 341-366.

[41] A. A. Peterson, R. P. Lachance, J. W. Tester, Ind. Eng. Chem. Res. 2010, 49, 2107-2117.

[42] A. Kruse, A. Krupka, V. Schwarzkopf, C. Gamard, T. Henningsen, Ind. Eng. Chem. Res. 2005, 44, 3013-3020.

[43] A. Kruse, P. Maniam, F. Spieler, Ind. Eng. Chem. Res. 2007, 46, 87-96.

[44] R. D. Bach, C. Canepa, J. Org. Chem. 1996, 61, 6346-6353.

[45] D. Sicinska, D. G. Truhlar, P. Paneth, J. Am. Chem. Soc. 2001, 123, 7683 7686.

[46] L. M. Phillips, J. K. Lee, J. Am. Chem. Soc. 2001, 123, 12067-12073.

[47] P. Ruelle, Chem. Phys. 1986, 110, 263-274.

[48] P. Ruelle, J. Am. Chem. Soc. 1987, 109, 1722-1725.

[49] J. An, L. Bagnell, T. Cablewski, C. R. Strauss, R. W. Trainor, J. Org. Chem. 1997, 62, 2505-2511.

[50] T. Erdmenger, C. R. Becer, R. Hoogenboom, U. S. Schubert, Aust. J. Chem. 2009, 62, 58-63.

[51] J. D. Campbell, J. A. Allaway, F. Teymour, M. Morbidelli, J. Appl. Polym. Sci. 2004, 94, 890-908.

[52] N. Akiya, P. E. Savage, Ind. Eng. Chem. Res. 2001, 40, 1822- 1831.

[53] X. Xu, M. J. Antal, Ind. Eng. Chem. Res. 1997, 36, 23-41.

[54] S. E. Hunter, C. E. Ehrenberger, P. E. Savage, J. Org. Chem. 2006, 71, 6229-6239.

[55] http://www.mathworks.com/help/toolbox/optim/ug/fmincon.html. $3^{\text {rd }}$ September 2011, date last accessed.

[56] K. Mishima, K. Matsuyama, $14^{\text {th }}$ International Conference on the Properties of Water and Steam in Kyoto, 350-353.

[57] S. Slae, R. Shapiro, J. Org. Chem. 1978, 43, $1721-1726$.

[58] H. Zheng, F. Meng, Struct. Chem. 2009, 20, 943-949.

[59] V. J. Nowlan, T. T. Tidwell, Acc. Chem. Res. 1977, 10, 252-258.

[60] W. M. Schubert, J. R. Keeffe, J. Am. Chem. Soc. 1972, 94, 559-566.

[61] T. E. Roe, J. T. Scanlan, D. Swern, J. Am. Chem. Soc. 1949, 71, 2215-2218.

[62] M. C. Cesa, S. L. Denman, US Patent No. 5,041,659, 1991.

[63] P. Duan, L. Dai, P. E. Savage, J. Supercrit. Fluids 2010, 51, 362-368.

[64] P. Valdez, J. G. Dickinson, P. E. Savage, Energy Fuels 2011, 25, 3235 3243.

Received: February 29, 2012

Published online on August 23, 2012 